\title{
Petrologia e geoquímica da soleira de Medicilândia, diabásio Penatecaua, PA
}

\author{
Juliana Costa ${ }^{1 *}$, Eleonora Maria Gouvêa Vasconcellos ${ }^{2}$, Carlos Eduardo de Mesquita Barros ${ }^{2}$, \\ Leonardo Fadel Cury ${ }^{2}$, Kaluan Frederico Virmond Juk ${ }^{1}$
}

\begin{abstract}
Resumo A soleira de Medicilândia, localizada em cidade homônima no estado do Pará, ocorre intrudida em rochas sedimentares da borda sul da Bacia do Amazonas e faz parte do evento magmático Penatecaua de idade triássico-jurássica. Tendo como objetivo geral definir a evolução do magmatismo responsável pela geração dessas rochas, foram realizados trabalhos de campo, coleta de amostras, análises petrográficas e estudos geoquímicos a partir de elementos maiores e elementos traço. A área mapeada abrange cerca de $300 \mathrm{~km}^{2}$ e é composta por diabásios e gabros cuja assembleia mineral primária compõe-se por augita, plagioclásio (andesina/labradorita), minerais opacos, apatita e quartzo. Quimicamente, as rochas são supersaturadas $\mathrm{em} \mathrm{SiO}_{2}$, classificadas como basaltos e andesito basaltos da série tolética, e são divididas em quatro grupos geoquímicos, de acordo com a análise de $\mathrm{mg}^{*}\left(\mathrm{MgO} /(\mathrm{MgO}+\mathrm{FeO})-\right.$ grupo 1: $\mathrm{mg}^{*}$ entre 0,5 e 0,6; grupos 2 e 3 com valores de $\mathrm{mg}^{*}$ entre 0,4 e 0,5 e 0,3 e 0,4 respectivamente; e grupo 4 com mg* entre 0,1 e 0,3. O grupo 4 apresenta teor de $\mathrm{TiO}_{2}$ entre 2 e $3 \%$, enquanto os demais possuem $\mathrm{TiO}_{2}<2 \%$. Os diagramas de variação indicam que a evolução do magma se deu por processo de cristalização fracionada com mudança de assembleia fracionante. O mapa faciológico mostra zoneamento na soleira onde as fácies primitivas localizam-se nas bordas, enquanto as evoluídas concentram-se no centro da intrusão. A hipótese mais provável de evolução da soleira indica uma origem relacionada com diferentes taxas de fusão parcial de uma mesma fonte, seguida por processo de cristalização fracionada.
\end{abstract}

Palavras-chave: rochas básicas; intrusivas; Magmatismo Penatecaua; Bacia do Amazonas.

\begin{abstract}
Petrology and geochemistry of Medicilândia sill, Penatecaua diabase, PA. The Medicilândia sill, located in the homonymous city in the Pará State (North Brazil), is an igneous body intruded in Paleozoic sedimentary rocks in the southern border of the Amazonas Basin, during the Penatecaua Magmatic Event, which occurred between the Triassic and Jurassic. In order to characterize the magmatic evolution that generated the sill, were performed field work with rock sampling, petrographic analysis and geochemical data analysis from major oxides, trace elements and rare earth elements. The studied area covers approximately $300 \mathrm{~km}^{2}$ and the lithology is represented by gabbros and diabase whose primary mineral assemblage is composed of augite, andesine/labradorite, opaque minerals, apatite and quartz. Chemically, the rocks are supersaturated in $\mathrm{SiO}_{2}$, classified as basalts and andesite basalts from a tholeiitic series, and are divided in four geochemical groups according to the $\mathrm{mg} *(\mathrm{MgO} / \mathrm{MgO}+\mathrm{FeO})$ analysis - group $1: \mathrm{mg}^{*}$ between 0.5 and 0.6 ; groups 2 and 3: $\mathrm{mg}^{*}$ between 0.4 and 0.5 and 0.3 and 0.4 respectively; group $4: \mathrm{mg}^{*}$ between 0.1 and 0.3 . The rocks from group 4 have $\mathrm{TiO}_{2}>2 \%$, whereas in the other groups the $\mathrm{TiO}_{2}<2 \%$. The variation diagrams indicate that the evolution of magma was characterized by fractionated crystallization process involving change in the fractionating assemblage. Facies map shows a zonation in the sill where the more primitive facies are located in the borders, whereas the more evolved are located in the central region of the intrusion. The most plausible hypothesis of the Medicilândia sill evolution is that the rock formed at different rates of partial melting from the same source, followed by fractional crystallization processes.
\end{abstract}

Keywords: basic rocks; intrusive; Penatecaua Magmatism; Amazonas Basin.

\section{INTRODUÇÃO Entre o Triássico e o}

Cretáceo, as bacias sedimentares do Amazonas, Solimões, Parnaíba e Paraná receberam grandes volumes e extensões de magmas básicos, seja na forma de intrusões ou derrames. Esses eventos magmáticos estão relacionados à formação do Oceano Atlântico Equatorial durante a ruptura do Pangea e consequente separação da América do Sul e da África.
As rochas básicas do Magmatismo Penatecaua (bacias do Amazonas e do Solimões) e das formações Mosquito e Sardinha (Bacia do Parnaíba) estão associadas ao início da abertura no Atlântico Equatorial. As intrusões e os derrames da Província Magmática do Paraná (Bacia do Paraná) associam-se à abertura da porção sul desse oceano (Mizusaki \& Thomaz Filho 2004).

\footnotetext{
${ }^{1}$ Programa de Pós-Graduação em Geologia, Departamento de Geologia, Universidade Federal do Paraná - UFPR, Curitiba (PR), Brasil.E-mails: jucosta@ufpr.br, kaluanjuk@gmail.com

${ }^{2}$ Departamento de Geologia, Universidade Federal do Paraná - UFPR, Curitiba (PR), Brasil. E-mails: eleonora@ufpr.br, cadubarros@ufpr.br, cury@ufpr.br

*Autor correspondente
} 
Na Bacia do Amazonas, o magmatismo está preservado na forma de intrusões, diques e soleiras, as quais estão encaixadas em rochas sedimentares paleozoicas. As melhores exposições das intrusivas básicas ocorrem na borda sul da bacia, onde afloram próximas aos municípios de Altamira, Medicilândia e Placas (Fig. 1). Na borda norte, os afloramentos localizam-se a noroeste da cidade de Monte Alegre.

A área selecionada para estudo consiste em uma soleira pertencente ao Magmatismo Penatecaua, localizada na cidade de Medicilândia no centro do estado do Pará. A intrusão apresenta cerca de $300 \mathrm{~km}^{2}$ de área aflorante e está encaixada em rochas sedimentares do Grupo Curuá e das formações Ererê e Maecuru na borda sul da Bacia do Amazonas, entre as coordenadas $260.000-320.000$ E e $9.600 .000-9.627 .300$ S. A região tem o acesso favorecido pela BR-230 (Rodovia Transamazônica) e pelas estradas vicinais, as quais transpõem a soleira nos sentidos nordeste/sudoeste e noroeste/sudeste respectivamente (Fig. 1).
Neste trabalho são apresentados os dados relativos aos trabalhos de campo realizados na área de estudo, os resultados das análises petrográfica e geoquímica, além de uma proposta de evolução magmática para a soleira.

O MAGMATISMO PENATECAUA As rochas intrusivas máficas da Bacia do Amazonas foram inicialmente denominadas "Diabásio Penatecaua" por Issler et al. (1974) ao descreverem as rochas aflorantes no rio Penatecaua, localizado na porção leste da soleira de Medicilândia. Caputo (1984) descreve o diabásio Penatecaua formado por rochas de assinatura toleítica, compostas por plagioclásio, piroxênio, ilmenita e magnetita com textura ofítica. Essas rochas ocorrem na forma de diques e soleiras de espessura variando de poucos metros até cerca de 200 metros, intrudidos nas rochas sedimentares paleozoicas da Bacia do Amazonas. De acordo com Marzolli et al. (1999), a média da soma das

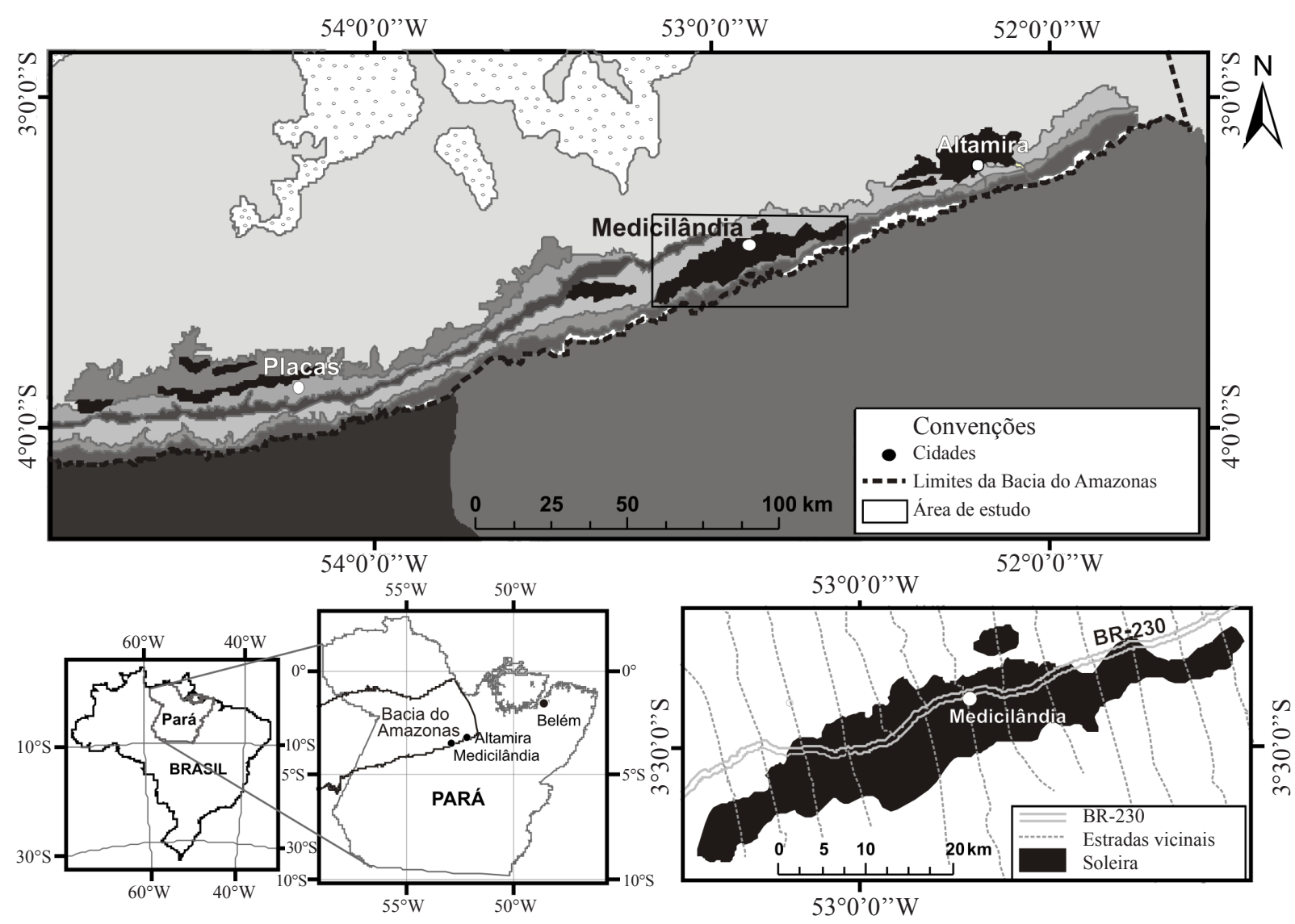

Estratigrafia
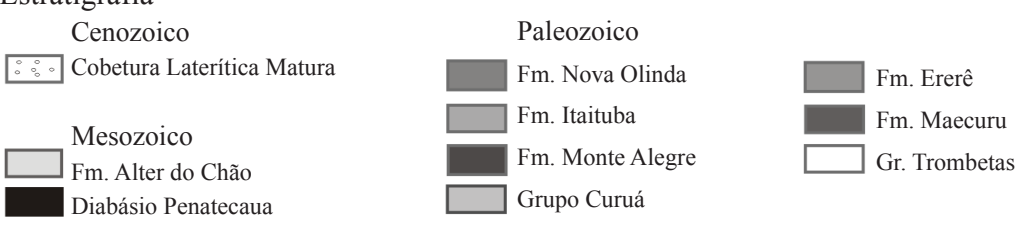

Figura 1 - Localização e acessos à soleira de Medicilândia, no estado do Pará. 
espessuras das soleiras é de $500 \mathrm{~m}$, e o volume estimado é de aproximadamente $4 \times 10^{5} \mathrm{~km}^{3}$. Os diques apresentam espessura variando de 5 a $25 \mathrm{~m}$ em afloramentos, porém dados sísmicos já detectaram diques com até $1 \mathrm{~km}$ de espessura. De acordo com Wanderley Filho et al. (2006), o magmatismo na Bacia do Amazonas é aparentemente controlado por grandes altos estruturais, formados antes das intrusões de rochas básicas. As soleiras são mais espessas próximo ao depocentro da bacia e mais adelgaçadas próximo aos altos estruturais.

Issler et al. (1974) consideram as rochas intrusivas básicas que compõem o diabásio Penatecaua como derivadas de uma ativação tectônica ou reativação ocorrida no Jurássico-Cretáceo. Thomaz Filho et al. (1974) realizaram 33 datações K/Ar, sendo 13 em plagioclásio e $20 \mathrm{em}$ rocha total, com o objetivo de determinar o intervalo de tempo abrangido pelo magmatismo. Os resultados obtidos permitem a identificação de dois ciclos magmáticos distintos, ambos com cerca de $50 \mathrm{Ma}$ de duração, associados à fragmentação do Pangea, onde o primeiro ciclo é atribuído ao período entre o fim do Permiano e o Triássico e foi associado pelos autores à abertura do Oceano Atlântico Equatorial. As idades mais ativas desse pulso magmático são definidas em 250, 230 e $200 \mathrm{Ma}$. O segundo ciclo configura a evolução do magmatismo na porção mais ocidental estudada pelos autores e é atribuído a reflexos do fraturamento, associados à abertura do Oceano Atlântico Sul, e tem como épocas mais ativas as idades entre 170 e $140 \mathrm{Ma}$.

Thomaz Filho et al. (2000) consideram que o processo de separação entre a América do Sul e a África iniciou no Triássico na margem equatorial brasileira e ocorreu de NW para SE, associado a manifestações magmáticas nas bacias do Amazonas, Acre, Solimões e Parnaíba. Thomaz Filho et al. (2008) descrevem que nas bacias do Amazonas e Solimões ocorreram dois picos magmáticos, ao redor de 215 Ma e 180 Ma, relacionados ao início da separação da América do Sul com a África. Na sequência da abertura do Oceano Atlântico, dessa vez na sua porção sul, ocorre um evento magmático a $130 \mathrm{Ma}$, representado por intensos derrames basálticos na Bacia do Paraná (Thomaz Filho et al. 2008).

Marzolli et al. (1999) propõem a denominação Central Atlantic Magmatic Province (CAMP) para agrupar os basaltos toleíticos que ocorrem em porções da América do Norte, África, Europa e América do Sul, incluindo o magmatismo Penatecaua. O modelo proposto, o qual define um único e breve evento magmático para a geração da CAMP, implica a presença de anomalias quentes do manto estendidas sob uma extensa área da crosta. Entretanto, os autores reconhecem a existência de outro modelo para a CAMP, no qual a origem do magmatismo estaria vinculada a anomalias termais rasas, refutando a hipótese de pluma do manto.

MATERIAIS E MÉTODOS Foram realizados trabalhos de campo na área de estudo onde foram descritos 63 afloramentos e coletadas 74 amostras de rocha. As lâminas para o estudo petrográfico foram confeccionadas no Laboratório de Laminação (LAMIN) e analisadas em microscópio petrográfico binocular do Laboratório de Mineralogia e Petrologia (LAPEMIN), ambos da UFPR. As análises por Fluorescência de Raios X (FRX) para a determinação dos 10 óxidos maiores $\left(\mathrm{SiO}_{2}, \mathrm{TiO}_{2}, \mathrm{Al}_{2} \mathrm{O}_{3}, \mathrm{FeO}, \mathrm{MnO}\right.$, $\mathrm{MgO}, \mathrm{CaO}, \mathrm{Na}_{2} \mathrm{O}, \mathrm{K}_{2} \mathrm{O}$ e $\mathrm{P}_{2} \mathrm{O}_{5}$ ) para 45 amostras de rocha foram realizadas no Laboratório de Análise de Minerais e Rochas (LAMIR) do DEGEOL da UFPR. Foram seguidos os procedimentos estabelecidos como padrão de preparação de rochas para a análise química por FRX. Para análise, foram selecionadas apenas porções não alteradas das rochas as quais foram britadas em moinho de mandíbula, quarteadas em quarteador de aço inoxidável e pulverizadas (granulometria igual a 325 mesh, menor que $44 \mu \mathrm{m}$ ) em panela de carbeto de tungstênio. As pérolas para a análise dos óxidos foram confeccionadas com adição de tetraborato de lítio, nitrato de amônio e brometo de lítio ao pó da rocha e fundidas em cadinhos de platina. Foram analisadas em espectrômetro de fluorescência de raios $\mathrm{X}$, por dispersão de comprimento de onda sequencial marca Philips/Panalytical modelo PW 2400, operando com fonte de raios X (tubo) de Rh de $3 \mathrm{~kW}$.

As análises de Elementos Terras Raras (ETR) (La, Ce, Pr, Nd, Sm, Eu, Gd, Tb, Dy, Ho, Er, Tm, $\mathrm{Yb}$ e Lu) e demais elementos traço (Ba, Co, Cs, Cu, Ga, Hf, Nb, Ni, Rb, Sr, Ta, Th, U, V, W, Y, Zn e Zr) para as 45 amostras foi realizada em espectrômetro de massa com fonte de plasma pelo laboratório ALS Laboratory Group, Mineral Division - ALS CHEMEX, em filial localizada em Belo Horizonte (MG). O método de análise consiste na preparação de 0,200 gramas de amostra à qual são adicionados 0,90 gramas de metaborato de lítio, e, após homogeneização, a mistura é fundida em forno a $1000^{\circ} \mathrm{C}$. O produto da fusão é então resfriado e dissolvido em 
$100 \mathrm{~mL}$ de solução de 4\% $\mathrm{HNO}_{3} / 2 \% \mathrm{HCl}$. Essa solução é na sequência analisada em espectrômetro de massa do tipo plasma ICP-MS.

GEOLOGIA LOCAL Em Medicilândia, Pará, a área de exposição da soleira abrange mais de $300 \mathrm{~km}^{2}$, e a melhor exposição de rochas ocorre em uma pedreira localizada no $\mathrm{km} 85$ da Rodovia Transamazônica, a $5 \mathrm{~km}$ da cidade. Outros afloramentos são encontrados nos leitos e cortes de estrada (Fig. 2A) e na forma de blocos (64-256 mm) e matacões ( $>256 \mathrm{~mm}$ ) dispersos nos campos e em meio aos cultivos de cacau.

Em campo, são observadas algumas feições e estruturas comuns às rochas originadas por intrusões básicas. Como exemplos, têm-se as disjunções colunares, definidas por planos verticais muitas vezes ondulados (Fig. 2B) e que formam prismas cujas bases podem ser quadradas, pentagonais ou hexagonais. Discordantes aos planos das disjunções ocorrem planos de fraturas abertas e preenchidas por calcita e quartzo (Fig. 2C).
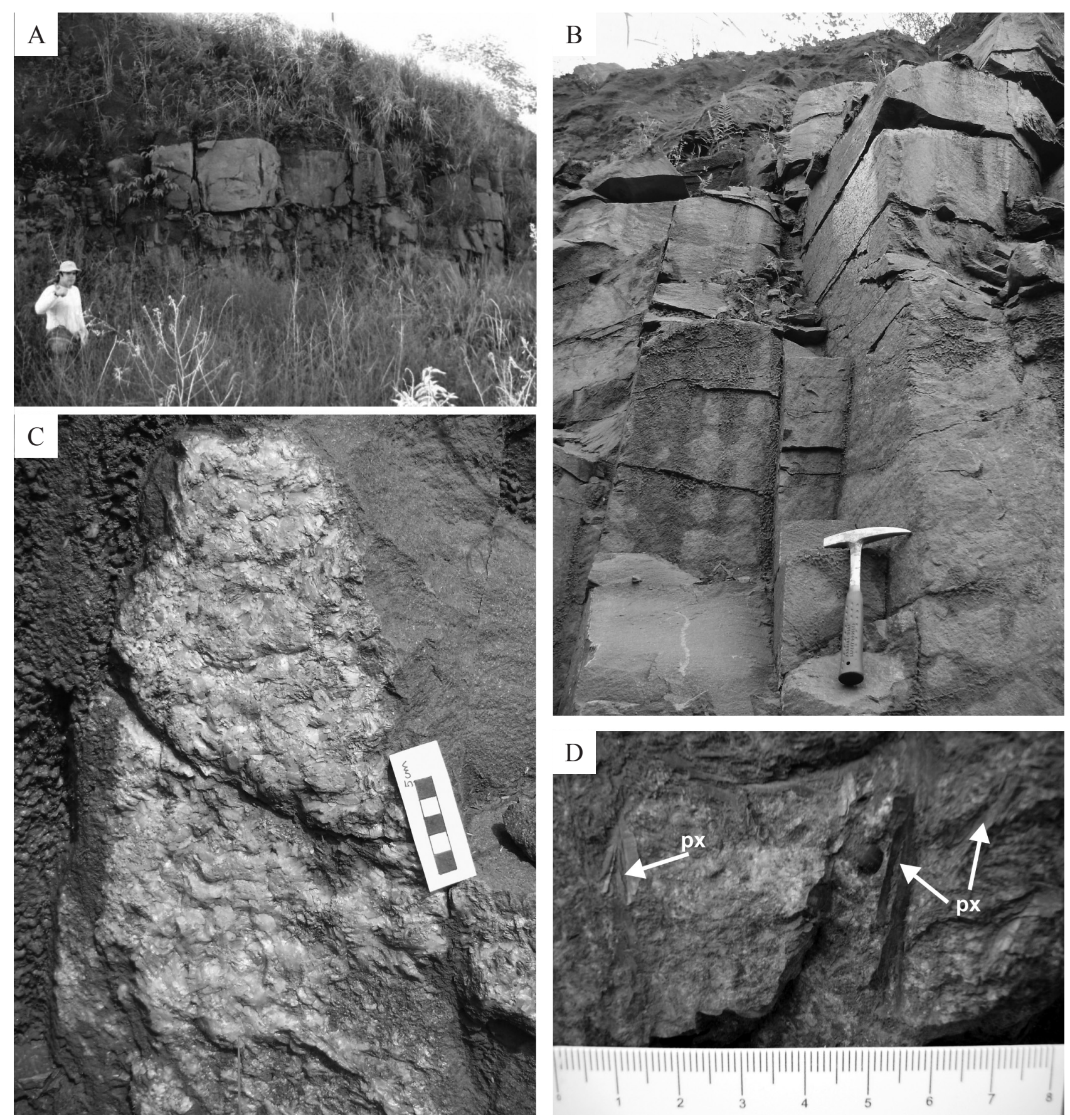

Figura 2 - (A) Afloramento de gabro em corte de estrada; (B) disjunções colunares vistas em perfil na pedreira do km 85 da BR-230; (C) fratura preenchida por calcita e quartzo em rochas da pedreira do $\mathrm{km} 85 \mathrm{da} B \mathrm{R}-230$; (D) presença de megacristais de piroxênio prismático de até 4,5 cm em gabro da soleira de Medicilândia. 
A soleira é composta por diabásios e gabros, separados de acordo com a granulação, com cores variando de cinza claro a escuro e cinza esverdeado, com índice de cor mesocrático a melanocrático, com porcentagem de máficos entre 40 e 65 . A assembleia mineral, definida macroscopicamente, é composta por piroxênio, plagioclásio, minerais opacos e sulfetos subordinados.

Macroscopicamente os diabásios são rochas faneríticas, holocristalinas, equigranulares, subofíticas a intergranulares e predominam em área aflorante em relação aos gabros. A granulação varia de fina, em que os cristais têm dimensões inferiores a $1 \mathrm{~mm}$, a média, na qual os cristais têm dimensões entre 2 e $5 \mathrm{~mm}$. Os gabros, por sua vez, são rochas faneríticas, holocristalinas, subofíticas e têm granulação grossa $(>5 \mathrm{~mm})$. Apresentam textura inequigranular grossa, ou textura inequigranular porfirítica, com a presença de megacristais de piroxênio prismático de até 4,5 cm (Fig. 2D).
PETROGRAFIA Ao microscópio, as rochas da soleira de Medicilândia foram texturalmente classificadas como gabros (granulação grossa) e diabásios (granulação fina a média). Os diabásios possuem textura equigranular fina a média e inequigranular glomeroporfirítica fina a média, enquanto nos gabros a textura é inequigranular e inequigranular porfirítica. A assembleia mineral primária é composta por augita, plagioclásio (andesina/labradorita), minerais opacos, apatita, quartzo e feldspato alcalino.

A augita é prismática, euédrica a subédrica de granulação média a grossa, ou anédrica granular fina, e perfaz entre 40 e $55 \%$ da composição modal das rochas. Ocorre na forma de microfenocristais e na matriz da rocha. Está frequentemente alterada para clorita, uralita, hornblenda e minerais opacos e, por vezes, apresenta zonamento composicional (Fig. 3A).

O plagioclásio, classificado como andesina/labradorita em microscópio perfaz entre 40 e
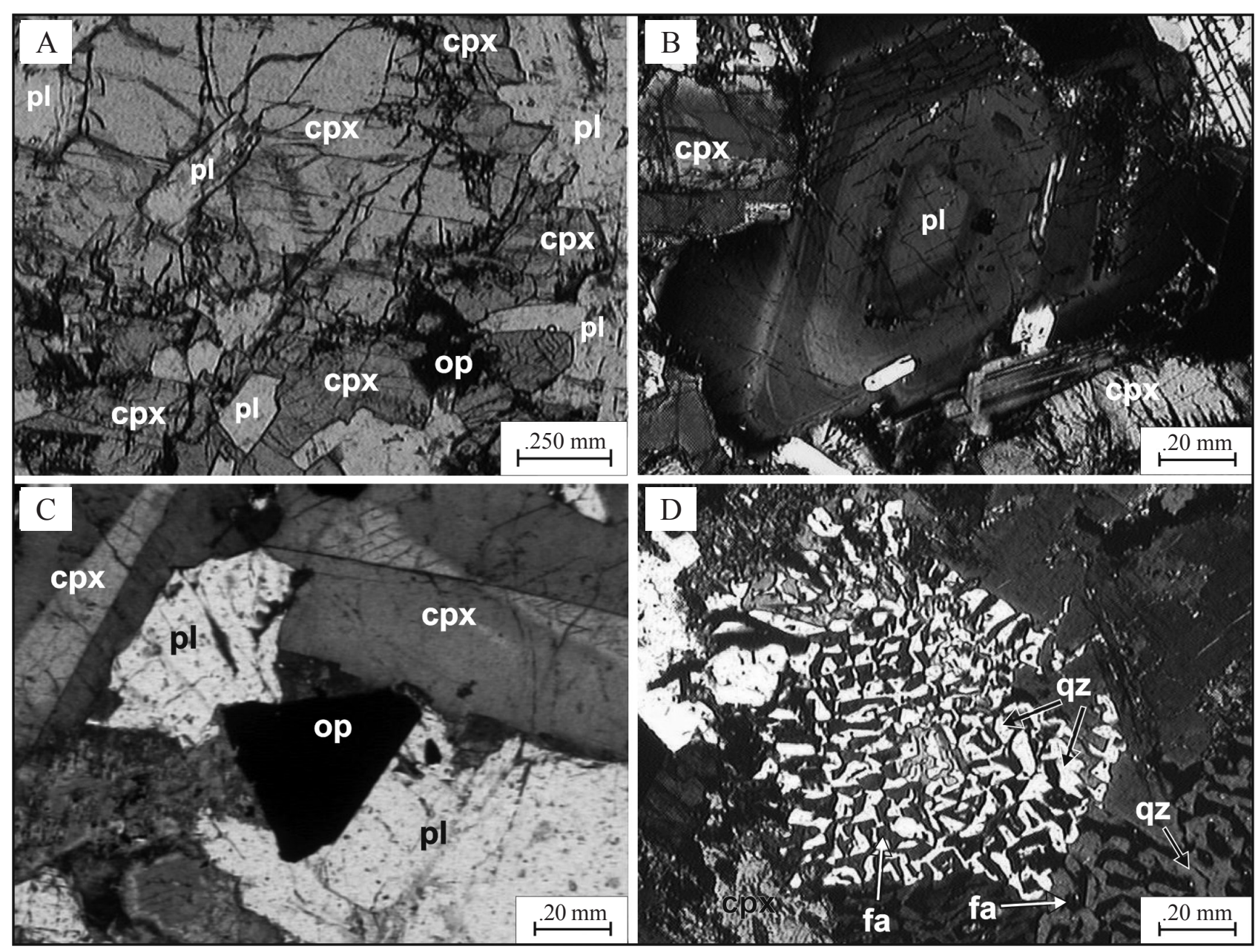

Figura 3 - Fotomicrografias (A) microfenocristal de clinopiroxênio com zonamento composicional, onde as bordas apresentam birrefringência mais elevada do que o centro do mineral (diabásio) (nicois cruzados (NX)); (B) cristal de plagioclásio com zonamento composicional descontínuo e inclusões de minerais opacos (diabásio) (NX); (C) mineral opaco de origem primária (diabásio) (nicois paralelos (N//)); (D) intercrescimento micrográfico de quartzo em feldspato alcalino (diabásio) (N//). cpx: clinopiroxênio, fa: feldspato alcalino, op: minerais opacos, qz: quartzo e pl: plagioclásio. 
$55 \%$ da composição modal das rochas e ocorre como cristais euédricos a subédricos ripiformes, de granulação fina, média ou grossa. Ocorre na forma de microfenocristais e na matriz da rocha. Com frequência, apresentam-se alterados para sericita e epidoto e, por vezes, observam-se cristais com zonamento composicional contínuo ou descontínuo (Fig. 3B).

Os minerais opacos primários não ultrapassam $5 \%$ da composição modal das rochas, onde ocorrem como cristais euédricos finos (Fig. 3C), presentes em seções quadradas e triangulares, inclusos na augita e no plagioclásio. Quando os opacos ocorrem como minerais secundários, perfazem até $10 \%$ da moda. São anédricos granulares finos, sobrecrescidos na augita, ou esqueletais de granulação média.

A apatita é um mineral acessório comum aos litotipos e ocorre em porcentagem subordinada. São cristais euédricos a subédricos, hexagonais ou prismáticos submilimétricos, geralmente inclusos no plagioclásio e na augita.

O quartzo primário é subordinado e ocorre na forma de cristais anédricos finos intersticiais à rocha ou compondo intercrescimento gráfico com o feldspato alcalino (Fig. 3D).

Há uma paragênese de alteração hidrotermal marcante, definida por minerais opacos, sericita, clorita, uralita, hornblenda, biotita, quartzo e epidoto (Fig. 4).

Os minerais opacos compõem a fase mineral mais frequente da paragênese hidrotermal. Ocorrem em todos os diabásios e gabros em porcentagens que

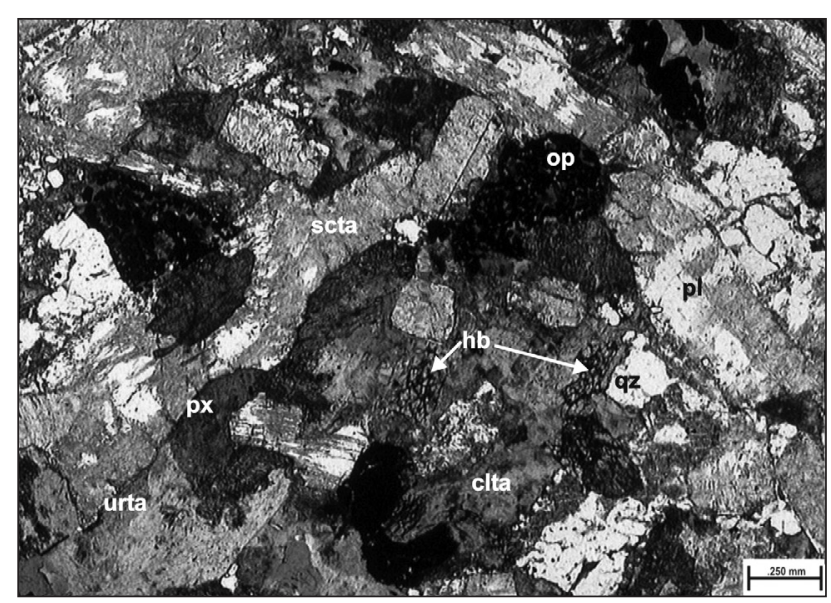

Figura 4 - Fotomicrografia de diabásio equigranular fino intensamente alterado, mostrando a paragênese de alteração hidrotermal. scta: sericita, px: piroxênio, urta: uralita, clta: clorita, qz: quartzo, hb: hornblenda e pl: plagioclásio. (nicois paralelos (N//)). variam de traço a até $10 \%$, em que as porcentagens modais mais elevadas estão nas rochas intensamente alteradas. Manifestam-se de duas formas distintas: com hábito anédrico, formato arredondado e granulação fina, e hábito esqueletal com granulação média. No primeiro caso, os minerais opacos estão sobrecrescidos no clinopiroxênio (Fig. 5A) e muitas vezes formam pseudomorfos desse mineral. Quando apresenta hábito esqueletal, esses minerais são intersticiais à rocha (Fig. 5B).

A clorita ocorre com granulação fina e hábito acicular ou fibroso, a biotita apresenta hábito subédrico e granulação fina a média, a hornblenda tem hábito subédrico e granulação fina a média, e a uralita, hábito anédrico fibroso e granulação fina a média. Esses minerais (clorita, biotita e uralita) desenvolvem-se nas bordas dos cristais de augita e podem ocorrer substituindo totalmente o cristal de clinopiroxênio (Figs. 5C and D).

A sericita tem hábito acicular e granulação fina. Ocorre preenchendo fraturas, ao longo dos planos de clivagem do plagioclásio e, nas amostras intensamente alteradas, substitui toda a superfície do plagioclásio (Fig. 5D). O epidoto ocorre como cristais anédricos, de granulação fina, associado à sericita como produto da saussuritização do plagioclásio.

O quartzo hidrotermal ocorre na forma de cristais anédricos de granulação fina a média. É raro encontrá-lo nas rochas pouco alteradas, porém é frequente nas rochas onde a alteração é intensa. Nessas rochas ocorre principalmente nas porções de menor granulação, ocupando os espaços entre os cristais de clinopiroxênio e plagioclásio (Fig. 5D).

GEOQUÍMICA Das 73 amostras coletas, foram selecionadas 45 que foram analisadas para óxidos maiores e elementos traço (incluindo Terras Raras). A Tab. 1 discrimina os dados dos óxidos em porcentagem peso e os valores da norma CIPW, ambos recalculados para a base anidra. $\mathrm{O}$ valor de $\mathrm{Fe}_{2} \mathrm{O}_{3 \text { tot }}$ foi transformado em $\mathrm{Fe}_{2} \mathrm{O}_{3}+\mathrm{FeO}$, aplicando-se a razão $\mathrm{Fe}_{2} \mathrm{O}_{3} / \mathrm{FeO}=0,2$ de acordo com Middlemost (1989). A Tab. 1 fornece também o ID (Índice de Diferenciação) de Thorton \& Tutle (1960), os valores de $\mathrm{mg} *(\mathrm{MgO} /(\mathrm{MgO}+\mathrm{FeO}))$ e LOI (Lost On Ignition). A Tab. 2 discrimina os elementos traço e Terras Raras analisados e também a soma dos elementos Terras Raras ( $\Sigma$ ETR). 

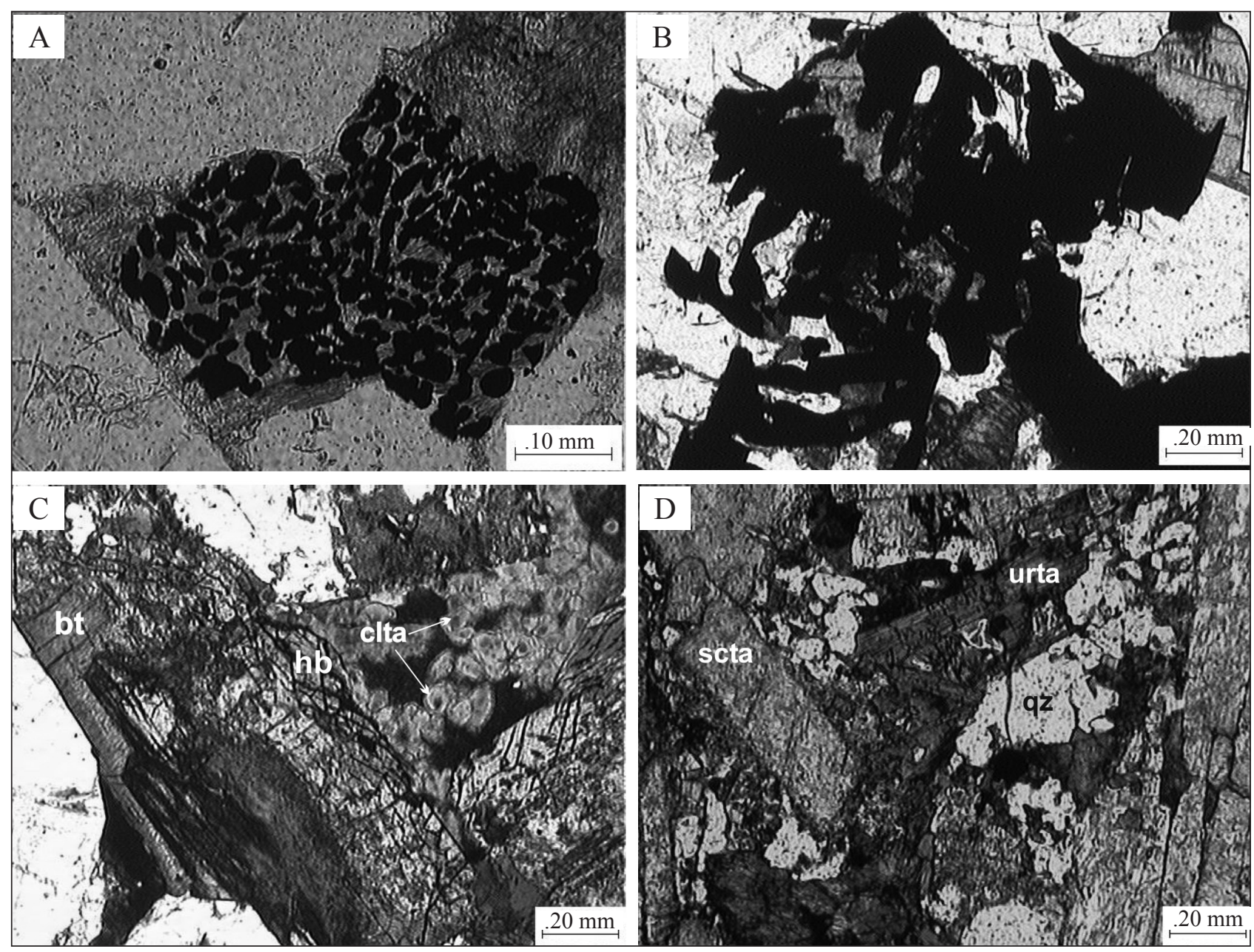

Figura 5-Fotomicrografias (A) minerais opacos anédricos sobrecrescidos em clinopiroxênio (diabásio) (nicois paralelos (N//)). Notar que os opacos estão desenvolvidos respeitando os limites do cristal de clinopiroxênio; (B) mineral opaco com hábito esqueletal sobrecrescido em clinopiroxênio (diabásio) (N//); (C) cristal de clinopiroxênio alterado na borda esquerda para biotita e na borda direita para anfibólio (gabro) (N//). Notar a presença de clorita em agregados fibrorradiados na porção superior direita da foto; (D) no centro da imagem, presença de uralita proveniente da alteração de clinopiroxênio, substituindo totalmente o mineral. Ao redor quartzo anédrico de origem hidrotermal, cristais de plagioclásio intensamente sericitizados (diabásio) (N//). bt: biotita, hb: hornblenda, clta: clorita, scta: sericita, qz: quartzo e urta: uralita.

Do ponto de vista geoquímico, todas as rochas analisadas são supersaturadas em $\mathrm{SiO}_{2}$ com quartzo normativo variando de 1,41 a $9,22 \%$ e uma rocha com $16,52 \%$. Os demais minerais normativos são plagioclásio (entre 38,77 e 54,79\%), ortoclásio (entre 2,95 e 11,52\%), diopsídio (entre 12,91 e $23,20 \%$ ), hiperstênio (entre 15,11 e $23,38 \%$ ), ilmenita (entre 1,77 e 5,49\%), magnetita (entre 3,12 e $5,71 \%$ ) e apatita (entre 0,19 e $0,90 \%$ ).

Considerando os óxidos maiores, as rochas da soleira são divididas em quatro grupos de acordo com suas características geoquímicas, como demonstrado no diagrama $\mathrm{FeO}$ x mg* (Fig. 6). O grupo 1, composto por rochas mais primitivas, apresenta os maiores valores de $\mathrm{mg} *(\mathrm{MgO} /$ $(\mathrm{MgO}+\mathrm{FeO}))$ que estão entre 0,5 e 0,6 . Os grupos 2 e 3 mostram valores de mg* intermediários, entre 0,4 e 0,5 e 0,3 e 0,4 , respectivamente. O grupo 4 é representado pelas rochas mais evoluídas, em que o mg* está entre 0,1 e 0,3 . As rochas desse último grupo possuem $\mathrm{TiO}_{2}>2 \%$, enquanto nos demais grupos o $\mathrm{TiO}_{2}$ é menor do que $2 \%$.

Para a confecção dos diagramas de variação, utilizou-se o $\mathrm{MgO}$ como índice de diferenciação. Esse índice é amplamente utilizado nas bibliografias de geoquímica de rochas básicas como ocorre, por exemplo, no trabalho de Piccirillo \& Melfi (1988) para a Província Magmática do Paraná. 


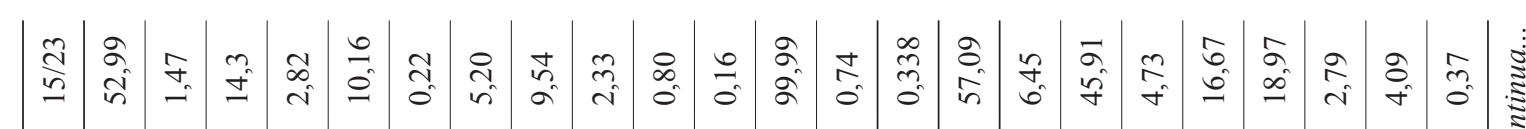

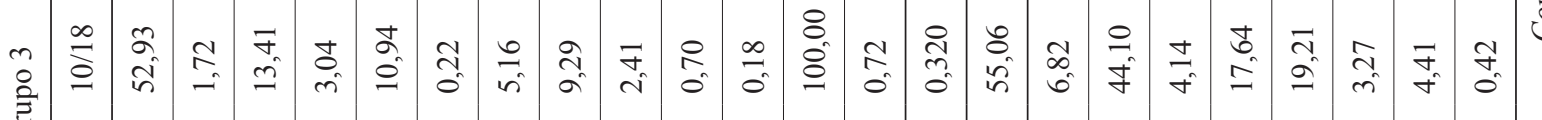

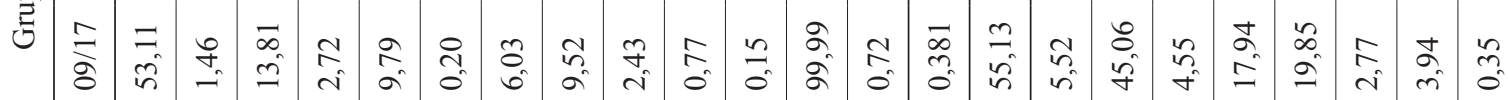

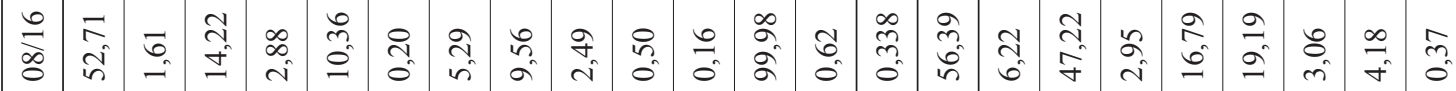

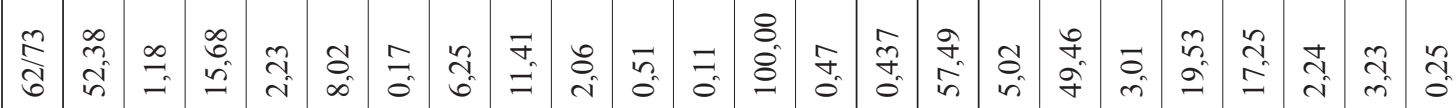

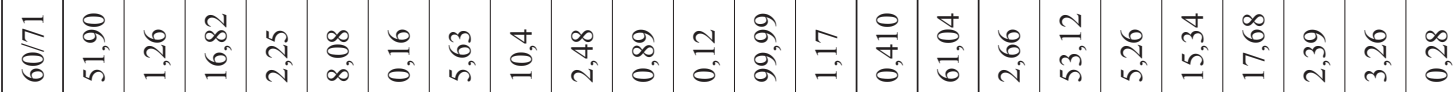

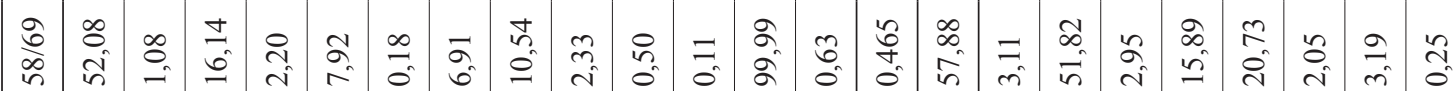

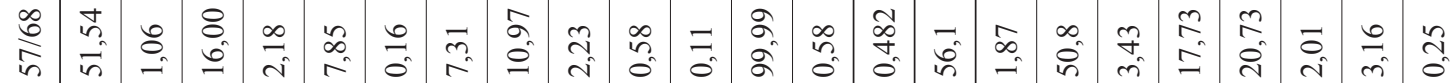

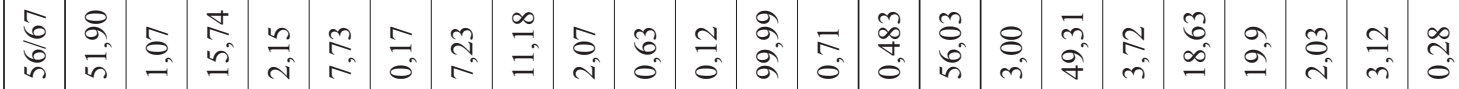

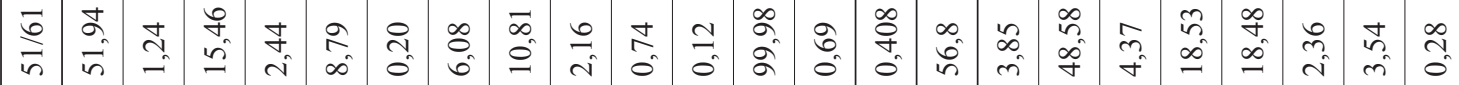
a

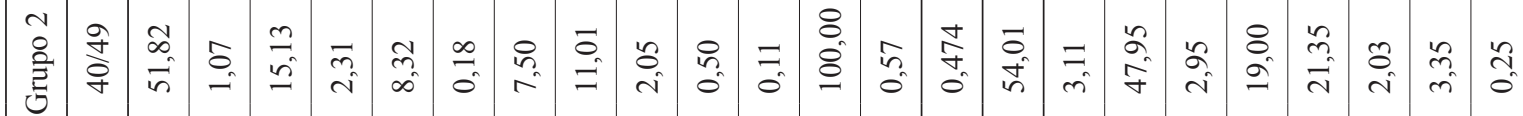

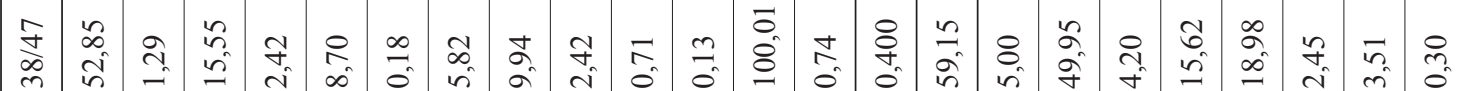

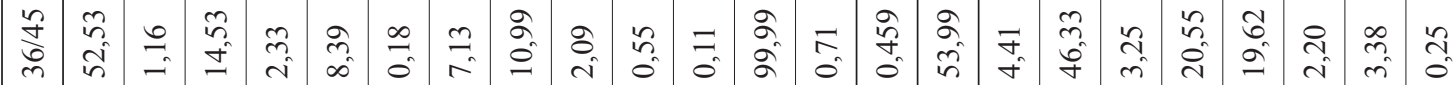

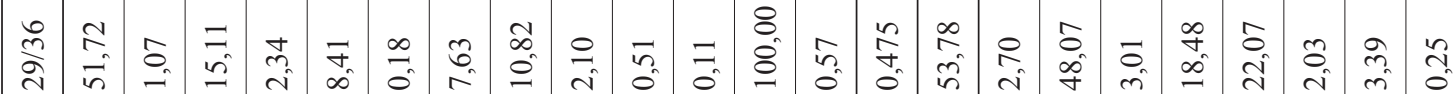

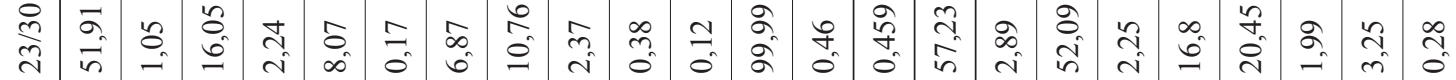

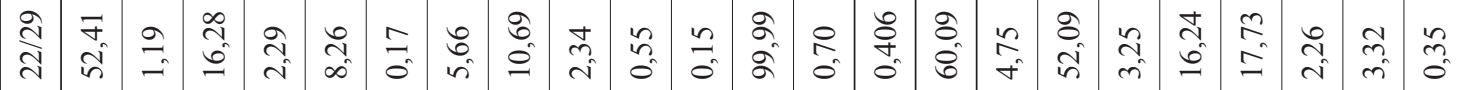

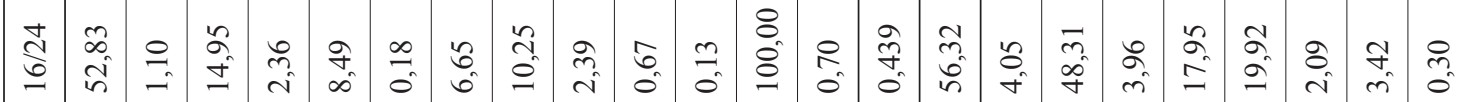

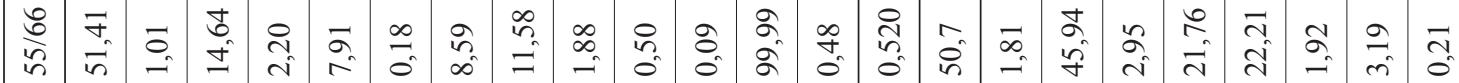

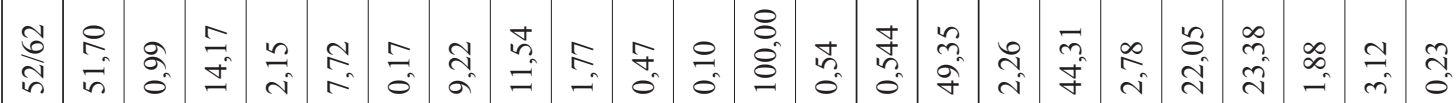

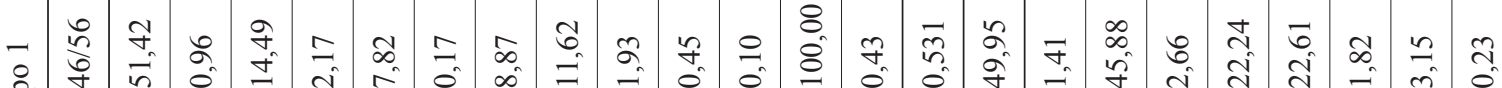
है

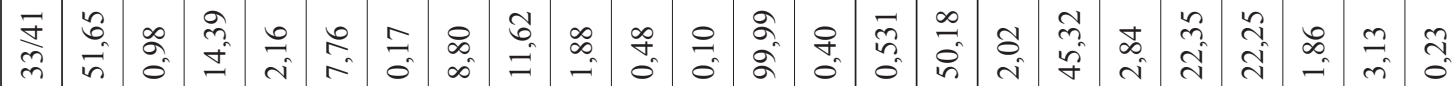

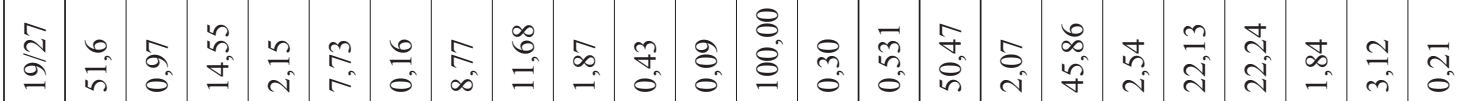

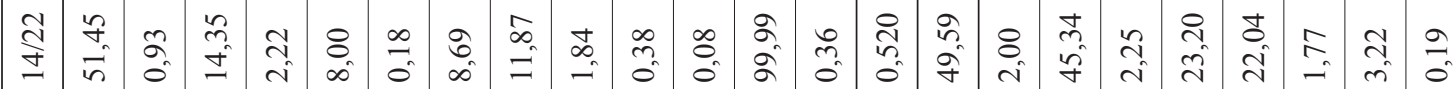




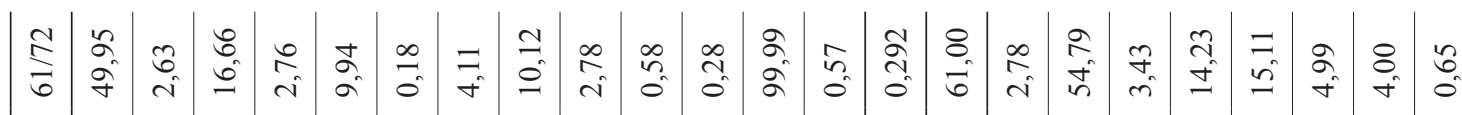

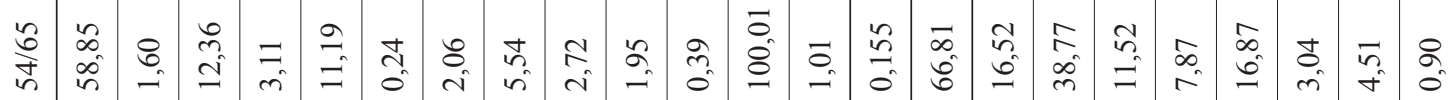

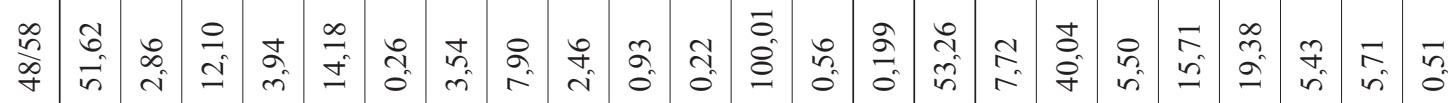

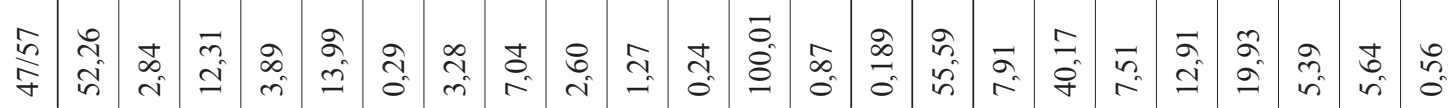

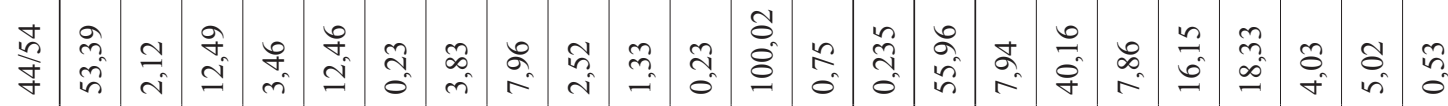

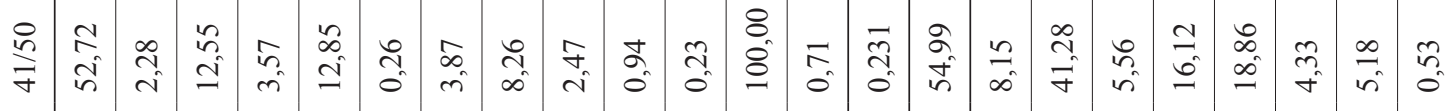

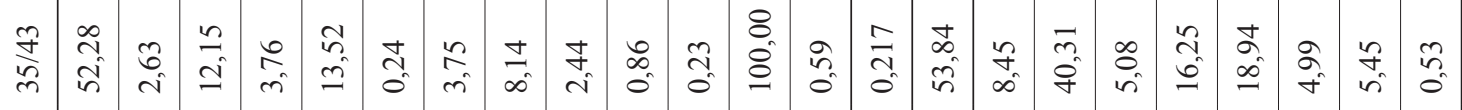

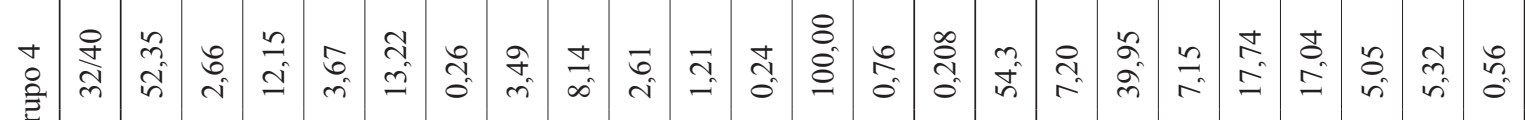

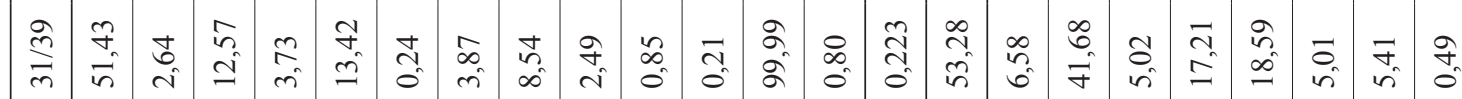

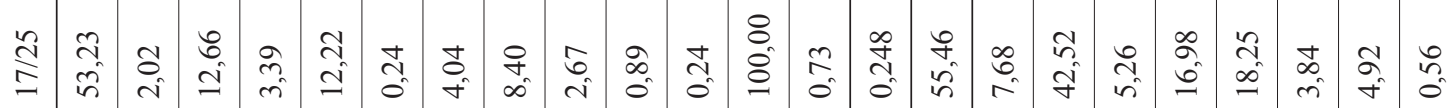

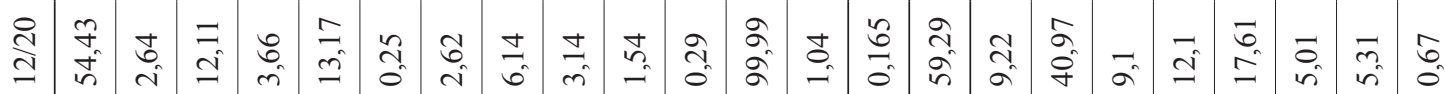

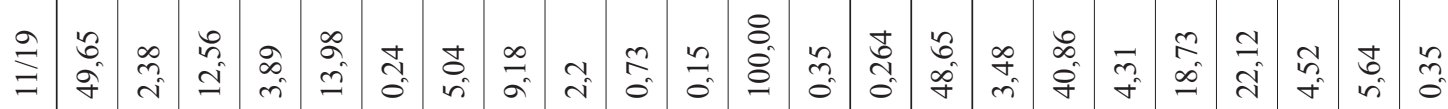

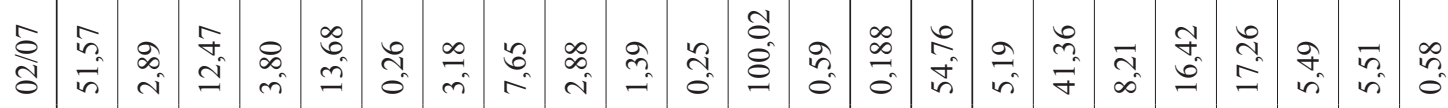

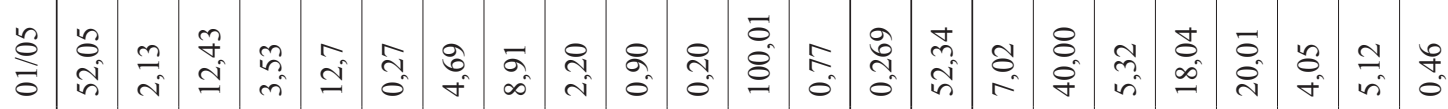

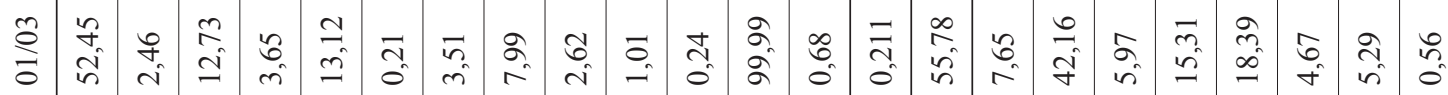

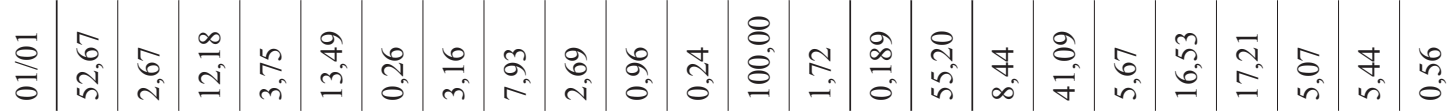

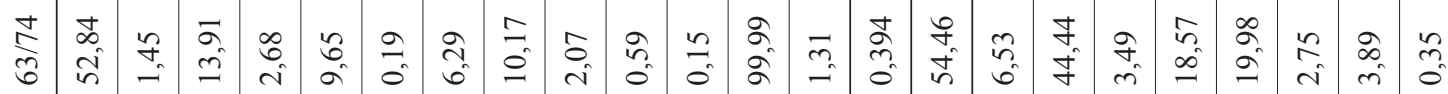

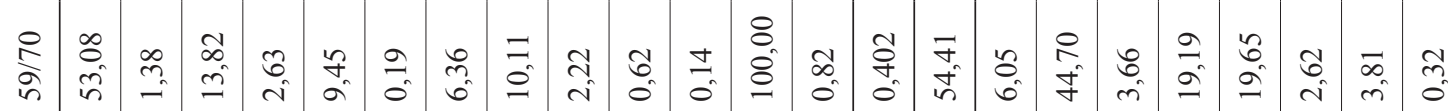

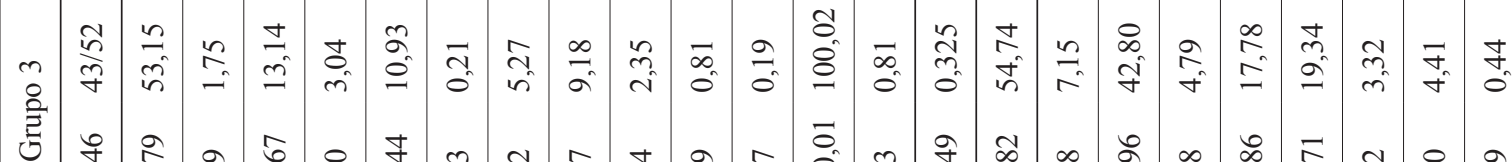

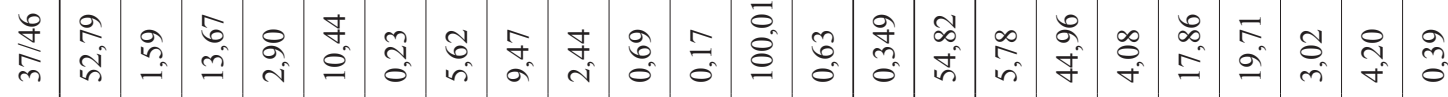

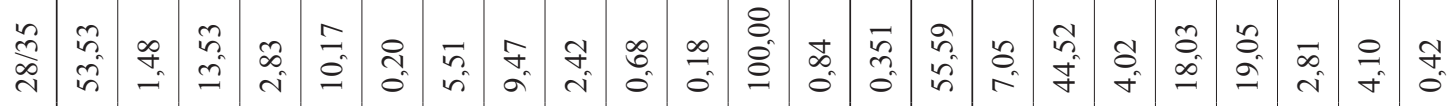

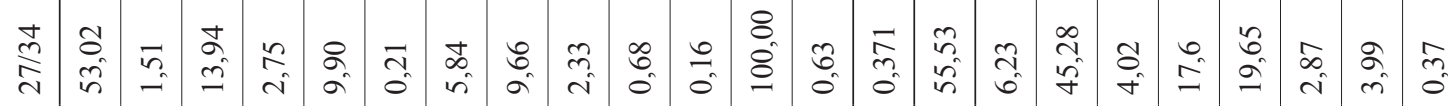




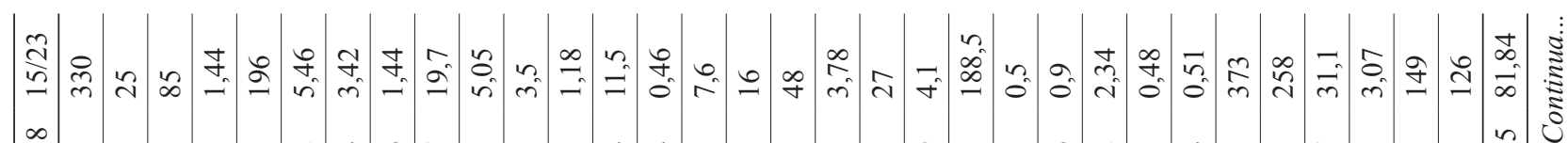

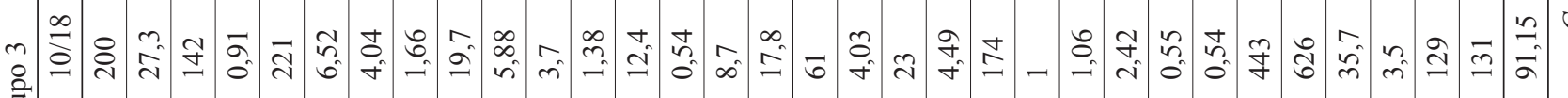

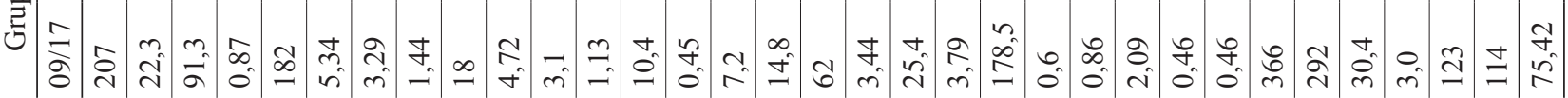

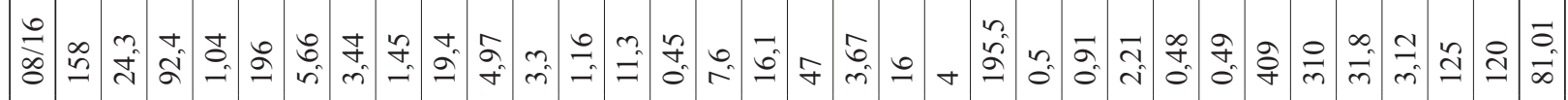

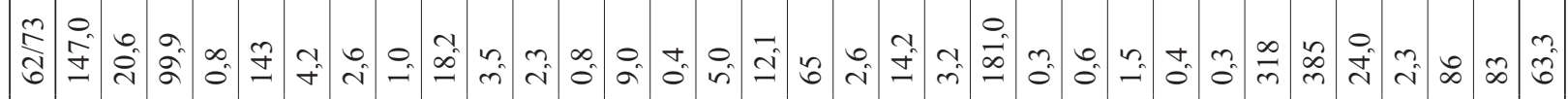

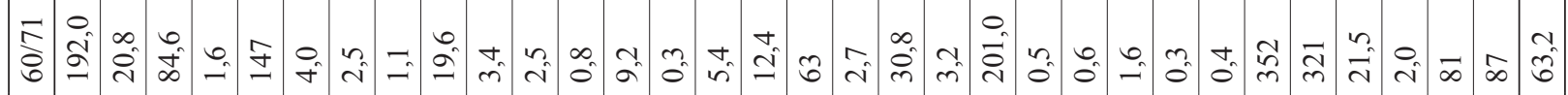

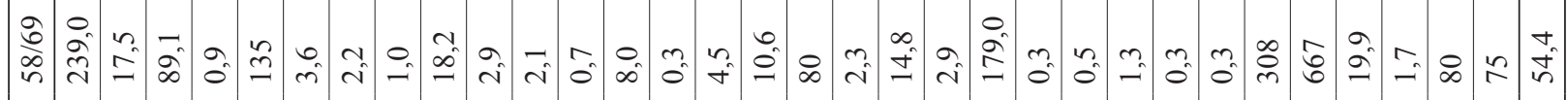

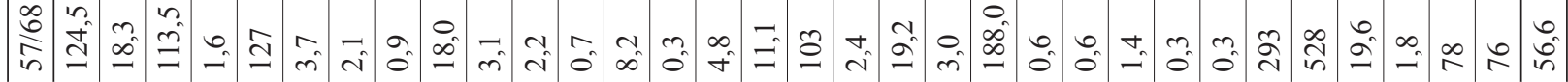

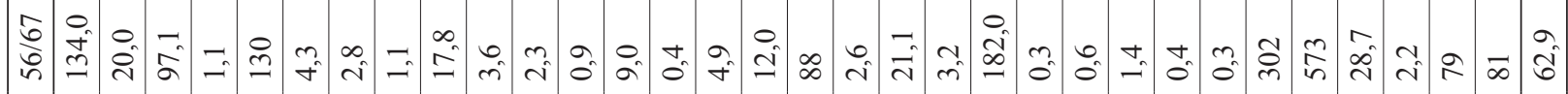

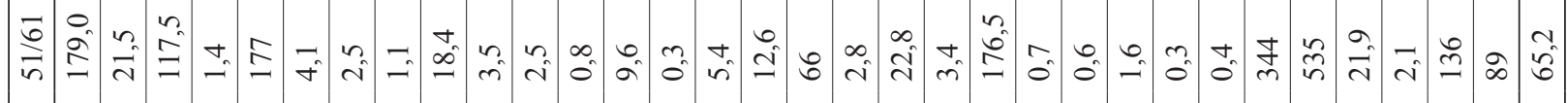

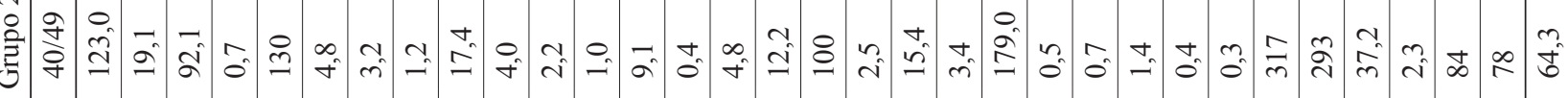

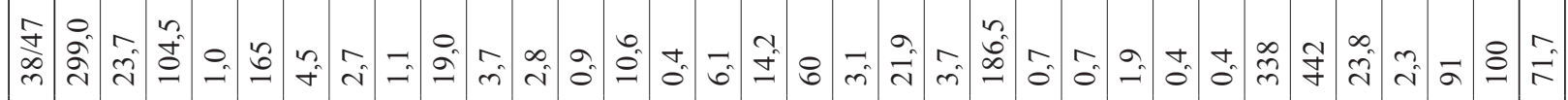

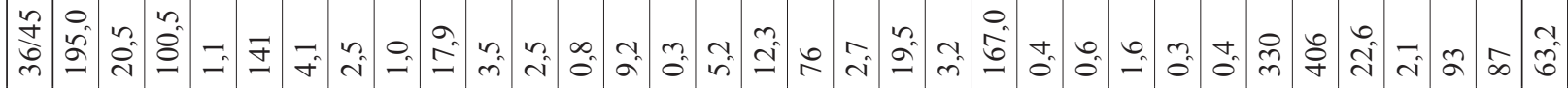

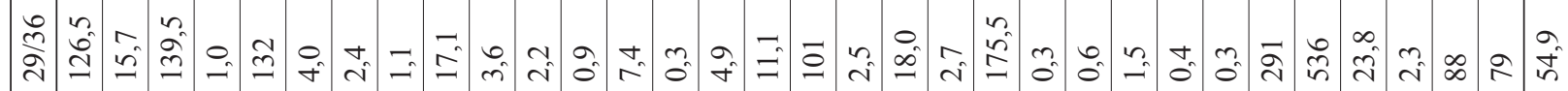

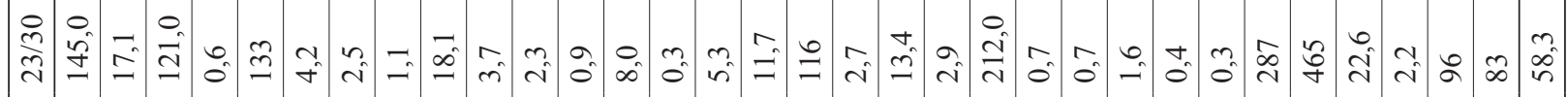

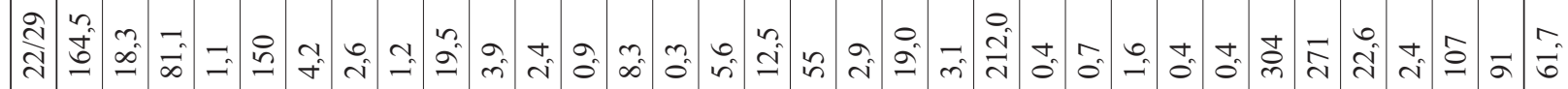

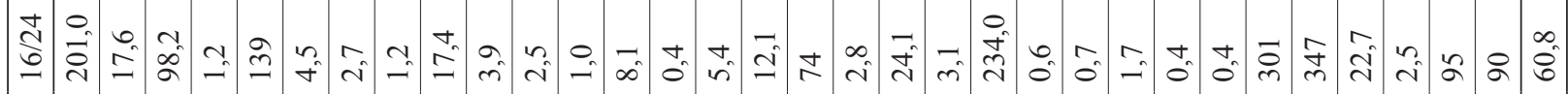

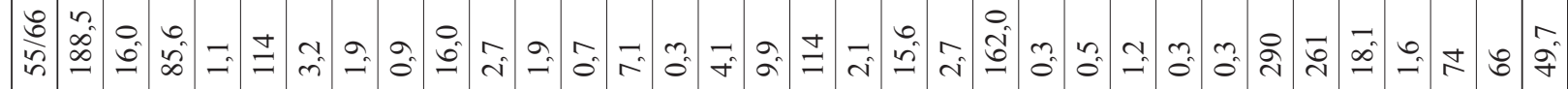

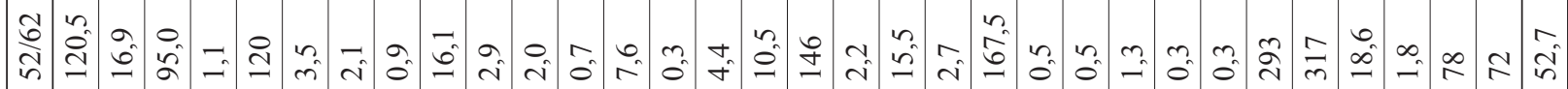

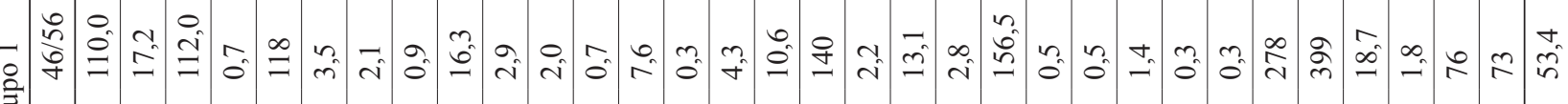

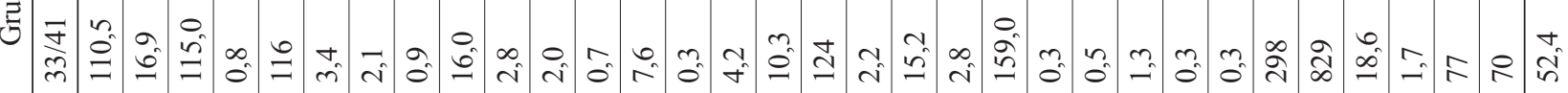

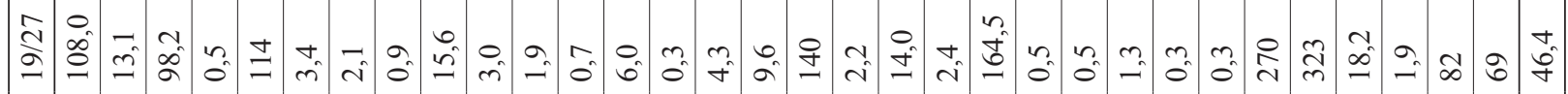

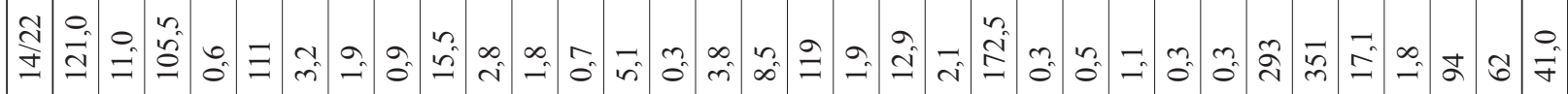
翼 כ) $\frac{\sqrt{8}}{8}$

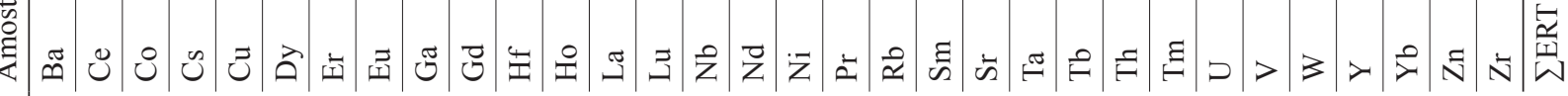

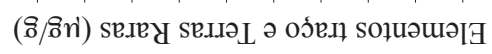




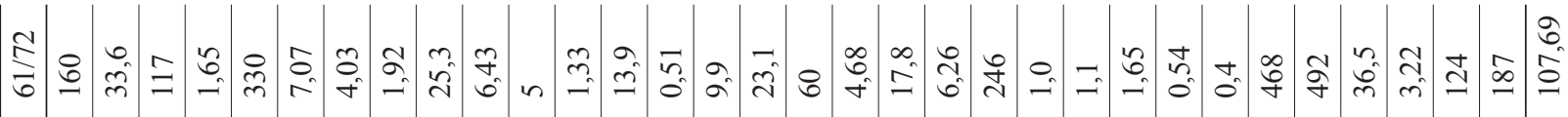

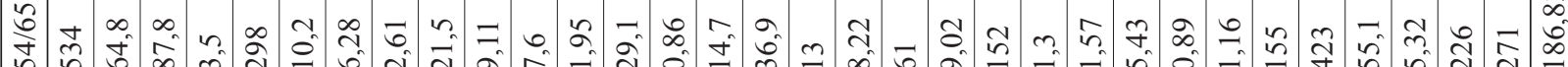

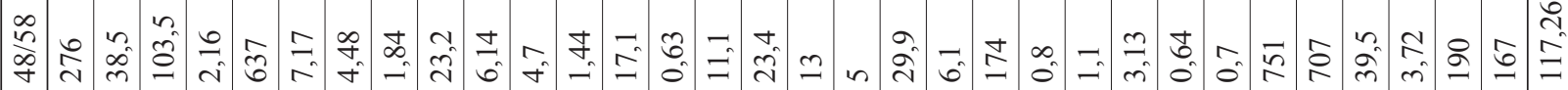

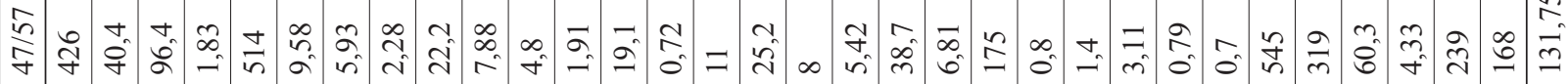

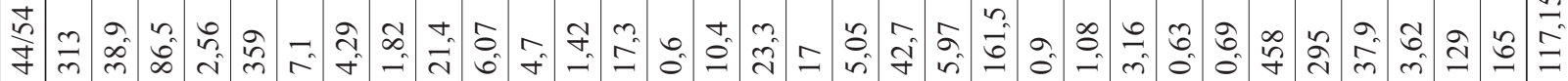

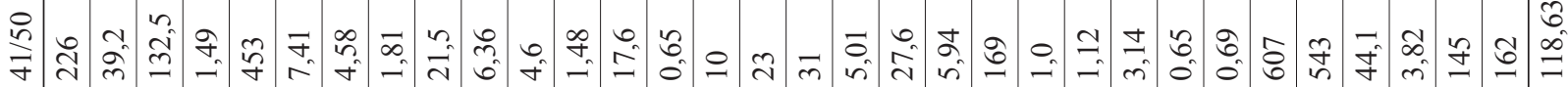

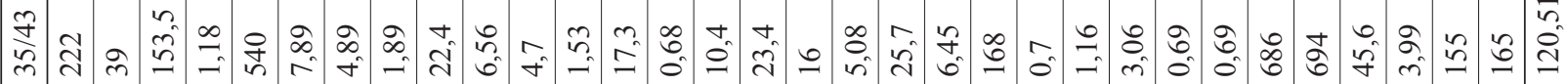

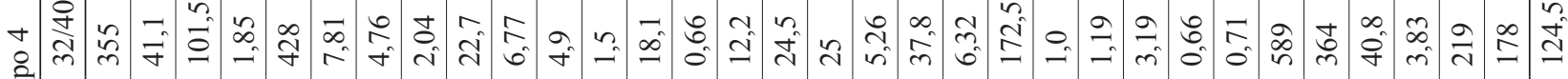

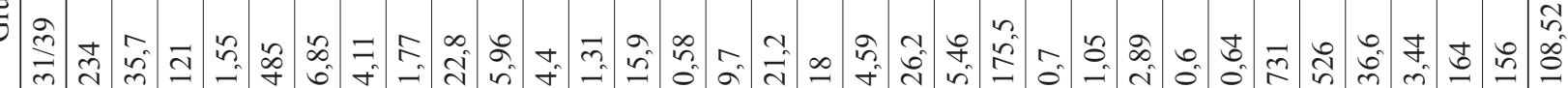

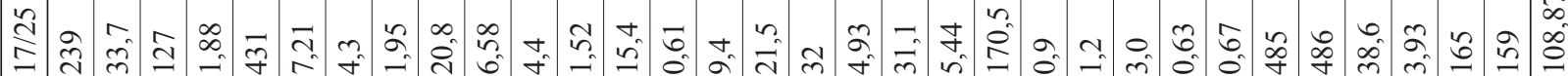

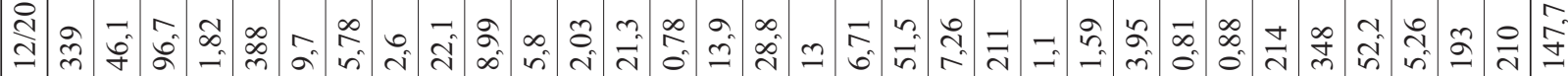

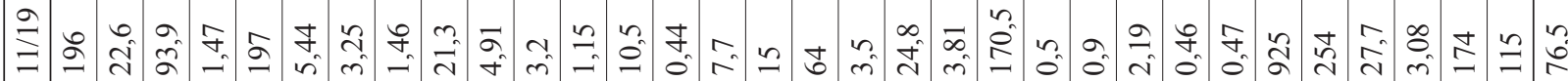

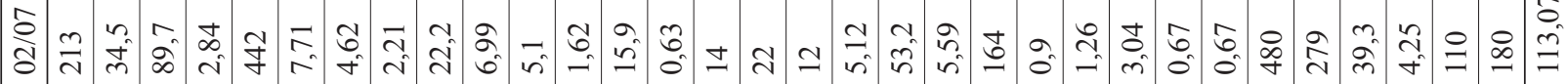

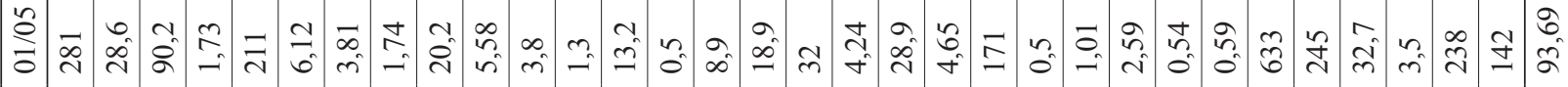

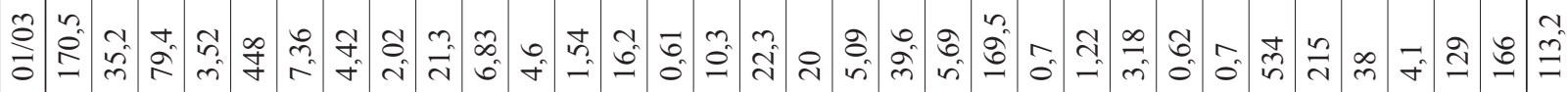

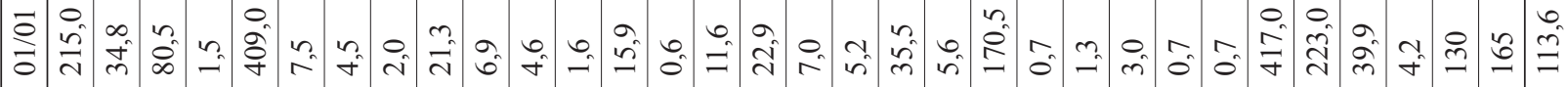

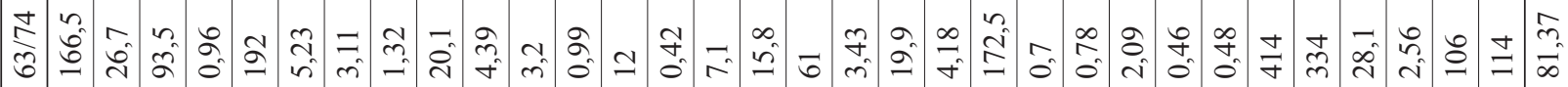

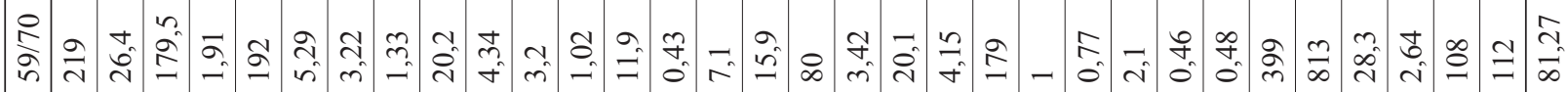

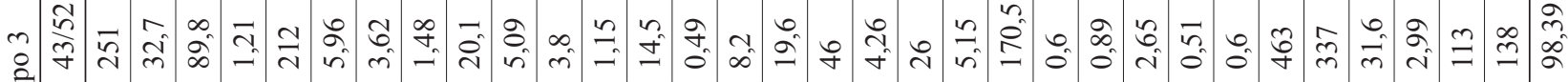
항

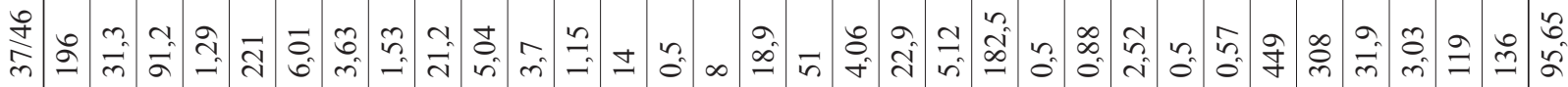

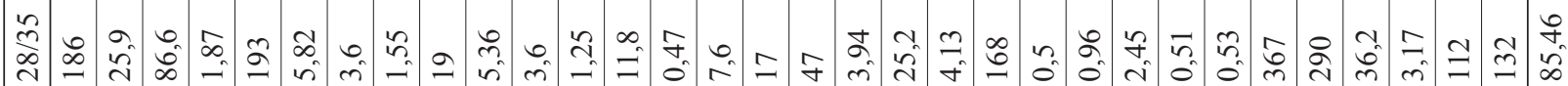

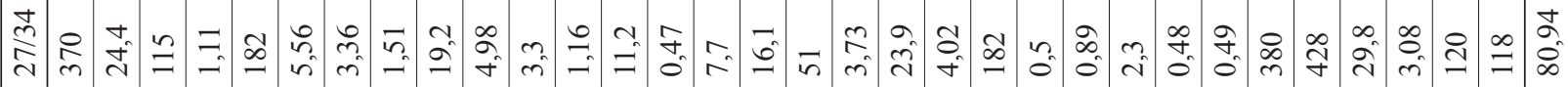

育究

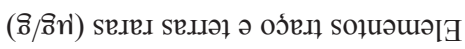




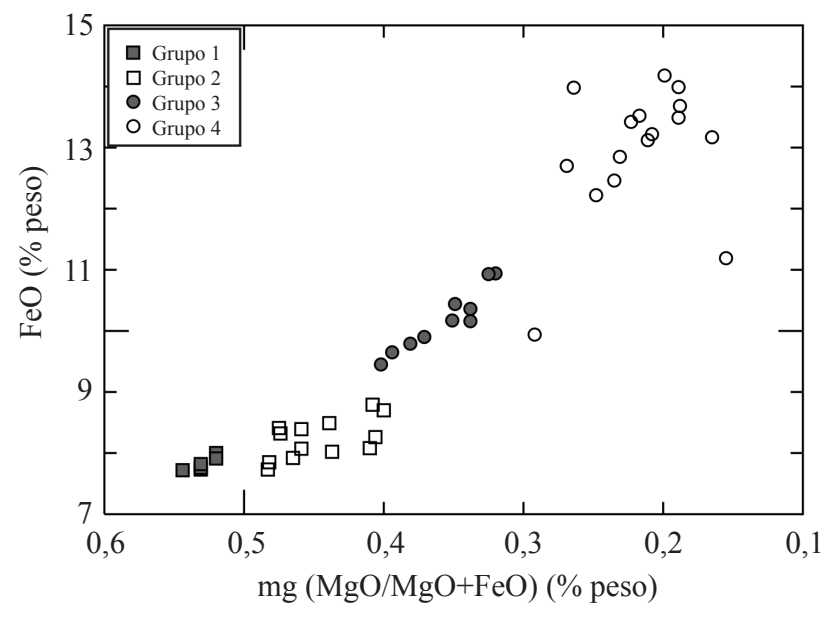

Figura 6 -Diagrama mg* $x \mathrm{FeO}$ no qual é definida a individualização de quatro grupos geoquímicos distintos para a soleira de Medicilândia.

A análise de diagramas de variação mostra uma tendência evolutiva para as rochas estudadas, que possuem correlações negativas para o $\mathrm{CaO}$ e Ni e positivas para $\mathrm{TiO}_{2}, \mathrm{FeO}, \mathrm{Fe}_{2} \mathrm{O}_{3}, \mathrm{Na}_{2} \mathrm{O}, \mathrm{K}_{2} \mathrm{O}$, $\mathrm{P}_{2} \mathrm{O}_{5}, \mathrm{Cu}, \mathrm{Y}$ e Zr (Figs. 7 e 8). Para a maior parte desses diagramas, o melhor ajuste dos pontos é definido por curvas polinomiais. No diagrama classificatório R1R2 de De La Roche et al. (1980) (Fig. 9), as rochas variam desde toleítos (grupos 1 e 2), andesi-basaltos (grupo 3 e parte do grupo 4), lati-andesitos a dacitos (grupo 4).

No diagrama AFM $\left(\left(\mathrm{Na}_{2} \mathrm{O}+\mathrm{K}_{2} \mathrm{O}\right) \times(\mathrm{FeO}+\right.$ $\mathrm{Fe}_{2} \mathrm{O}_{3}$ ) x MgO) (Irvine \& Baragar 1971) (Fig. 10), as rochas pertencem à série toleítica e configuram padrão típico com enriquecimento em $\mathrm{FeO}_{\mathrm{t}}$. Nesse diagrama, podem-se observar os quatro grupos geoquímicos onde as rochas mais primitivas (grupo 1) são as mais ricas em $\mathrm{MgO}$ e na sequência há o enriquecimento em $\mathrm{FeO}_{\mathrm{t}}$, passando pelas rochas dos grupos 2 e 3 até chegar às do grupo 4, que são as mais ricas em $\mathrm{FeO}_{\mathrm{t}}$ e mais evoluídas.

De acordo com o diagrama de Jensen (Al $\left.\mathrm{x}\left(\mathrm{Fe}^{2+}+\mathrm{Fe}^{3+}+\mathrm{Ti}\right) \mathrm{x} \mathrm{Mg}\right)($ Jensen \& Pyke 1982) (Fig.11), as rochas são principalmente toleíticas, e os grupos 1 e 2 concentram-se na porção de alto $\mathrm{MgO}$, enquanto os grupos 3 e 4 na porção de alto $\mathrm{FeO}$.

Em diagrama multielementar, normalizado para o manto primitivo de Sun \& McDonough (1989) (Fig. 12), o padrão das assinaturas é suave e observa-se anomalia positiva de $\mathrm{Cs}, \mathrm{K}$ e $\mathrm{Pb}$ e negativa de $\mathrm{Nb}$ e $\mathrm{P}$ para todas as rochas, e anomalia negativa de $\mathrm{Sr}$ para os grupos 3 e 4. No diagrama de Terras Raras (Fig. 13), normalizado para os condritos de Sun \& McDonough (1989), observa-se importante fracionamento entre os grupos de rochas, em que a razão $\mathrm{La} / \mathrm{Lu}_{\mathrm{N}}$ varia de 2,02 a 3,63. O padrão da assinatura geoquímica é retilíneo e indica fracionamento pouco significativo de ETR leves em relação aos pesados.

A ausência de anomalia negativa em Eu para todo o conjunto de 45 amostras indica que o fracionamento de plagioclásio, por processo de cristalização fracionada, não foi significativo. A concentração de ETR pesados de mais de dez vezes o condrito sugere a ausência de granada na fonte.

MAPA DE FÁCIES GEOQUÍMICAS Não é possível separar as rochas no campo com base nas características macroscópicas e na petrografia, as fácies geoquímicas são muito semelhantes. Por esse motivo, o mapa de fácies da Fig. 14 foi elaborado com base na ocorrência e distribuição dos grupos geoquímicos individualizados na área de estudo. Desse modo, cada um dos quatro grupos geoquímicos representa uma fácies geoquímica. Os limites das fácies foram inferidos de acordo com a localização e classificação geoquímica das rochas.

Esse mapa é uma proposta de divisão faciológica para demonstrar a variação composicional existente na soleira. Em geral, as fácies constituem faixas estreitas alongadas na direção NE, de forma concordante ao maior eixo da intrusão. As rochas mais primitivas, grupo 1, distribuem-se em duas faixas localizadas na borda sudeste da soleira, em contato com as rochas sedimentares da bacia do Amazonas. Apresentam granulação fina $(<1 \mathrm{~mm})$ com raros cristais de augita e plagioclásio de $2 \mathrm{~mm}$ de dimensão. O grupo 2 é definido por duas faixas localizadas na borda sudeste, logo acima do grupo 1, duas faixas na borda noroeste e uma porção isolada também a noroeste, todas em contato com as rochas sedimentares da bacia. O grupo 3 é constituído por três faixas, uma na porção oeste da soleira, uma na borda noroeste e outra na porção leste da borda noroeste. As rochas do grupo 4, formado pelas rochas mais evoluídas, distribuem-se ao longo de uma faixa de posição central na soleira.

Em suma, o mapa mostra um zoneamento geoquímico na soleira onde as rochas menos evoluídas distribuem-se nas bordas da intrusão enquanto as mais evoluídas concentram-se na porção central desta. No entanto, a precisão do mapa de fácies está 

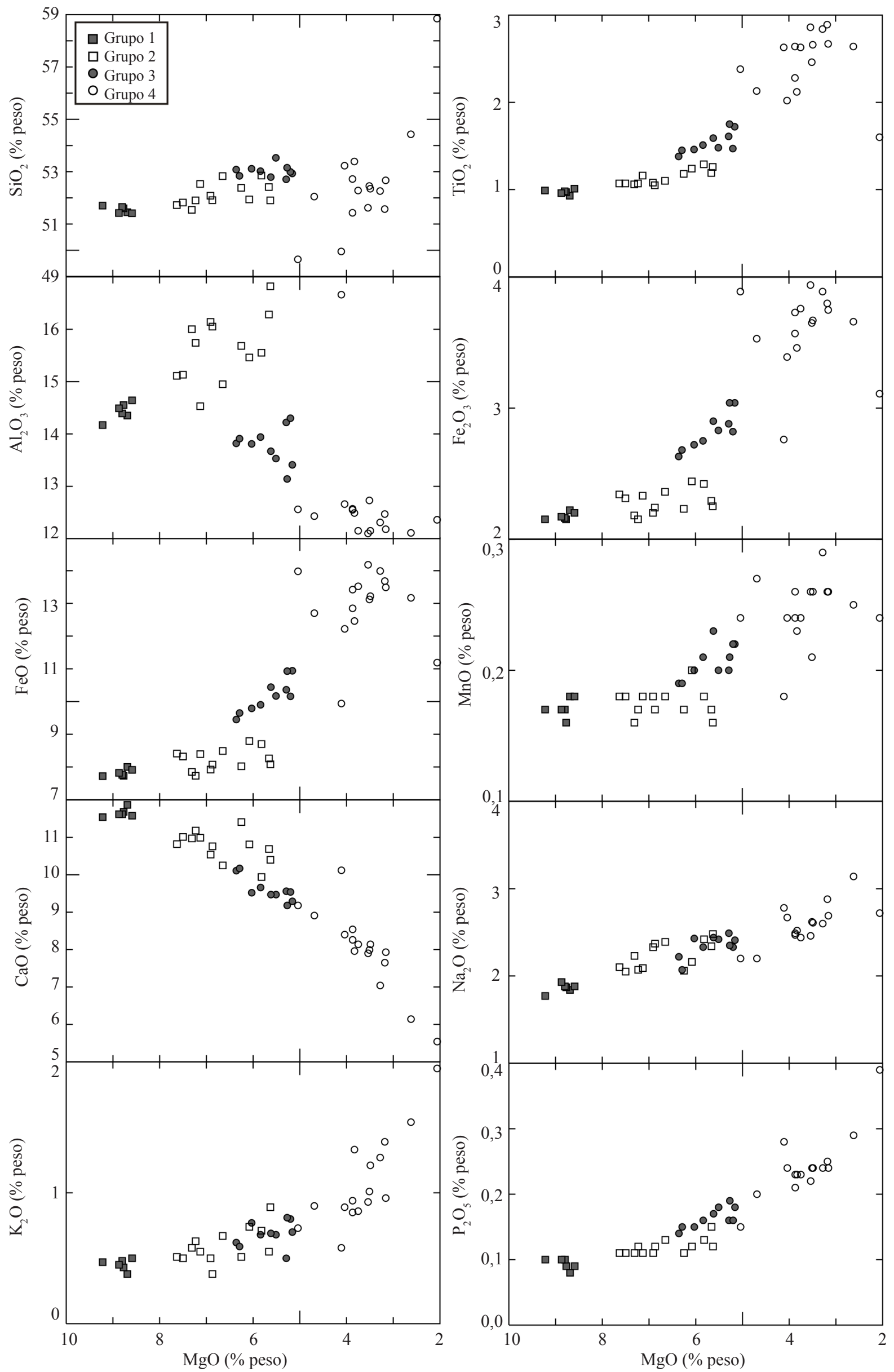

Figura 7 - Diagramas de variação, para óxidos maiores, utilizando MgO como índice de diferenciação para as rochas da soleira de Medicilândia. 

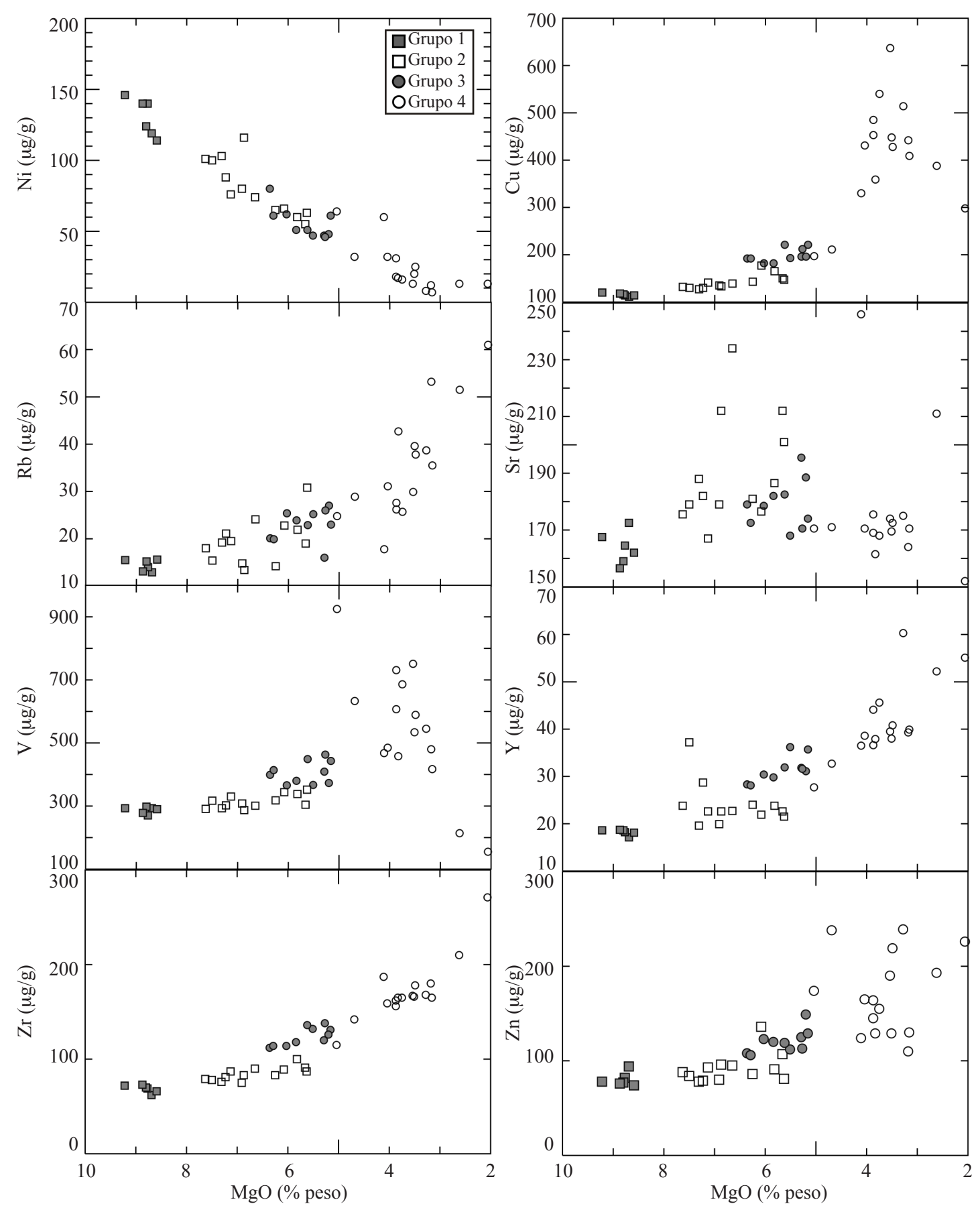

Figura 8-Diagramas de variação, para elementos traço analisados por Fluorescência de Raios X, utilizando $\mathrm{MgO}$ como índice de diferenciação para as rochas da soleira de Medicilândia.

vinculada à amostragem realizada. Por causa dessa limitação, os contatos traçados são inferidos e podem variar caso se faça um estudo de maior detalhe. Outro problema está relacionado ao fato de alguns afloramentos ocorrerem na forma de blocos e matacões; por isso, deve-se considerar a possibilidade de que alguns desses blocos ou matacões possam não estar na sua posição original.

\section{CARACTERÍSTICAS GEOQUÍMICAS E PROCESSOS GERADORES O estudo da soleira,}

com a individualização das rochas em quatro grupos geoquímicos com características distintas, permite avaliar a evolução geoquímica da intrusão, assim como estabelecer correlação com as rochas da Província Magmática do Paraná (PMP). O magmatismo Penatecaua e a PMP representam eventos magmáticos de caráter toleítico ocorridos em bacias sedimentares intracratônicas, bacias do Amazonas e do Paraná respectivamente, e ambos os eventos têm origem relacionada à formação do Oceano Atlântico Equatorial durante a ruptura do Pangea. Os grupos 


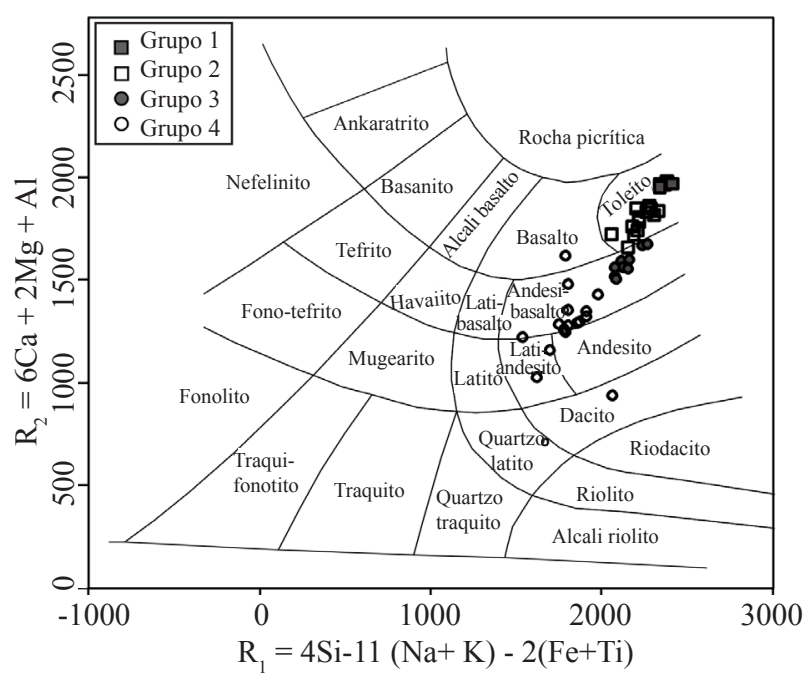

Figura 9 - Diagrama R1R2, R1 $=4 \mathrm{Si}-11(\mathrm{Na}+\mathrm{K})$ $2(\mathrm{Fe}+\mathrm{Ti}) \times \mathrm{R} 2=6 \mathrm{Ca}+2 \mathrm{Mg}+\mathrm{Al}$ (De La Roche et al. 1980) para as rochas da soleira de Medicilândia.

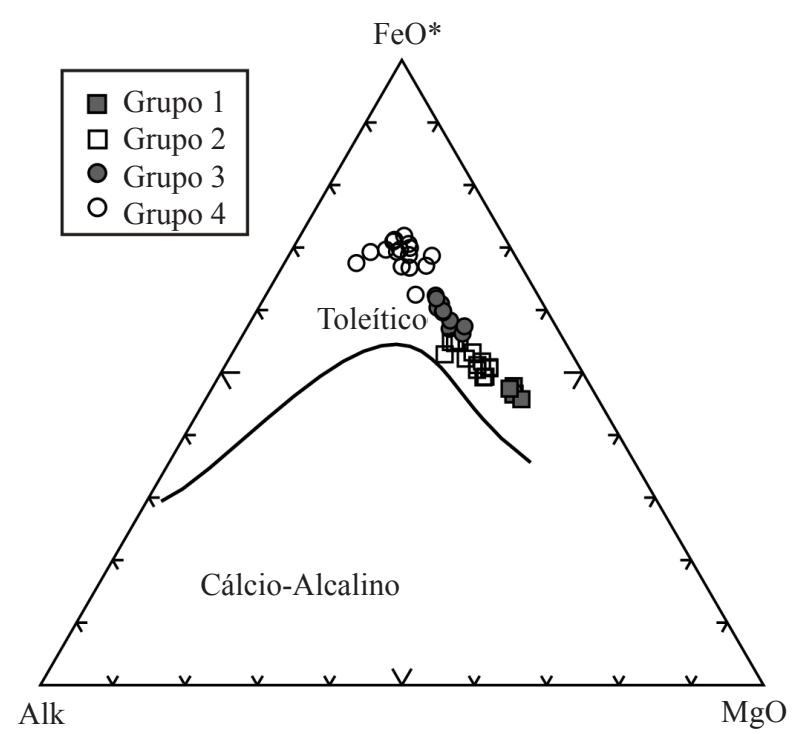

Figura 10 - Diagrama AFM, $\left(\mathrm{Na}_{2} \mathrm{O}+\mathrm{K}_{2} \mathrm{O}\right) \times(\mathrm{FeO}$ $\left.+\mathrm{Fe}_{2} \mathrm{O}_{3}\right) \times \mathrm{MgO}$ (Irvine \& Baragar 1971) para as rochas da soleira de Medicilândia.

1, 2 e 3 da soleira de Medicilândia apresentam baixo teor de $\mathrm{TiO}_{2}(<2 \%)$, assim como ocorre com os basaltos de baixo $\mathrm{TiO}_{2}$, tipos Gramado, Esmeralda e Ribeira (Peate et al. 1992) da PMP. O grupo 4 possui rochas com alto teor de $\mathrm{TiO}_{2}(>2 \%)$ e os mais elevados teores de $\mathrm{P}_{2} \mathrm{O}_{5}$, Zr, Hf, Ta e Y, semelhante ao que ocorre com os basaltos de alto $\mathrm{TiO}_{2}$, tipos Urubici, Pitanga e Paranapanema (Peate et al. 1992) da PMP.

O importante fracionamento de elementos traço e ETR observado entre os diferentes grupos de rocha nos diagramas multielementares (Figs. 12 e 13) sugere três possibilidades de gênese para a soleira de Medicilândia. A primeira refere-se à origem

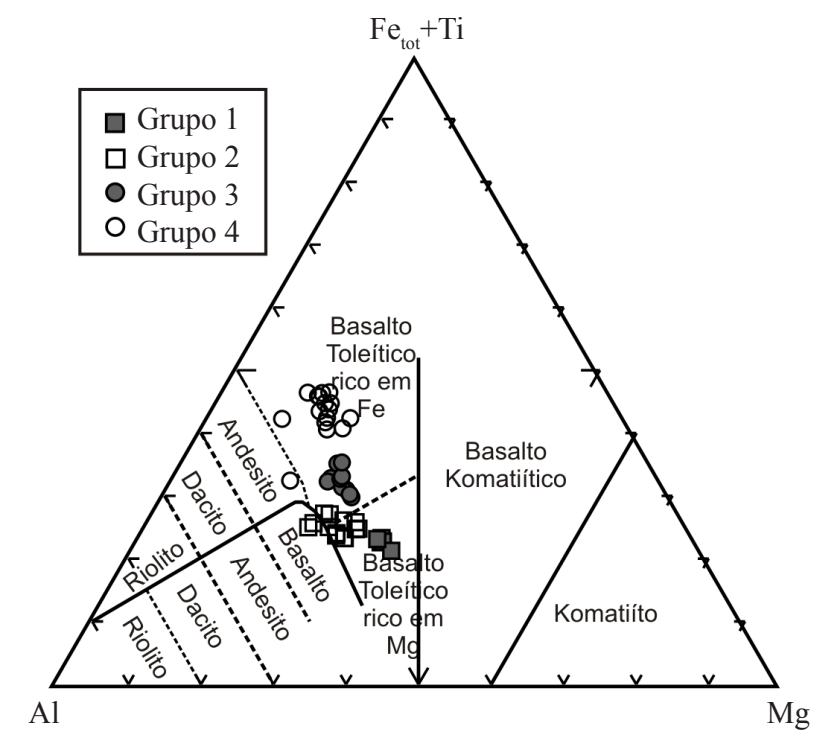

Figura 11 - Diagrama de Jensen, Al $x\left(\mathrm{Fe}^{2+}+\mathrm{Fe}^{3+}+\right.$ Ti) $x \mathrm{Mg}$ em porcentagem cationica (Jensen \& Pyke 1982) para as rochas da soleira de Medicilândia.

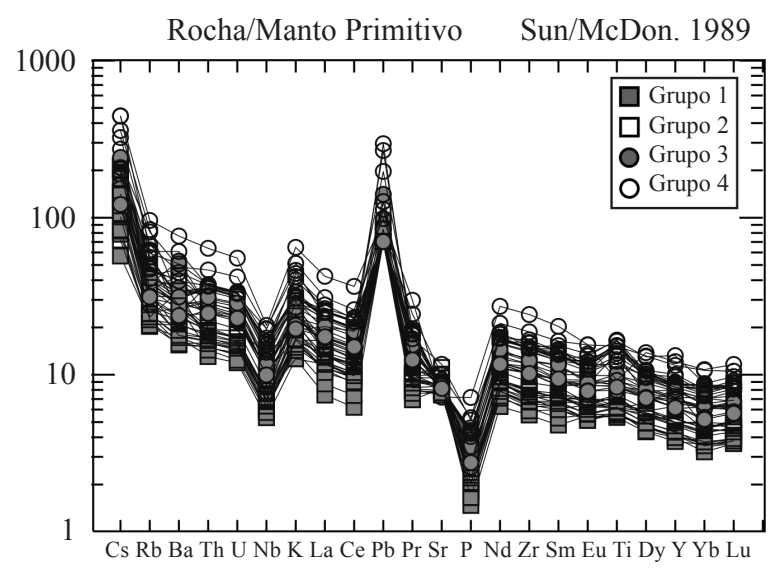

Figura 12 - Diagrama multielementar para elementos traço normalizado pelo manto primitivo de Sun \& McDonough (1989) para as rochas da soleira de Medicilândia.

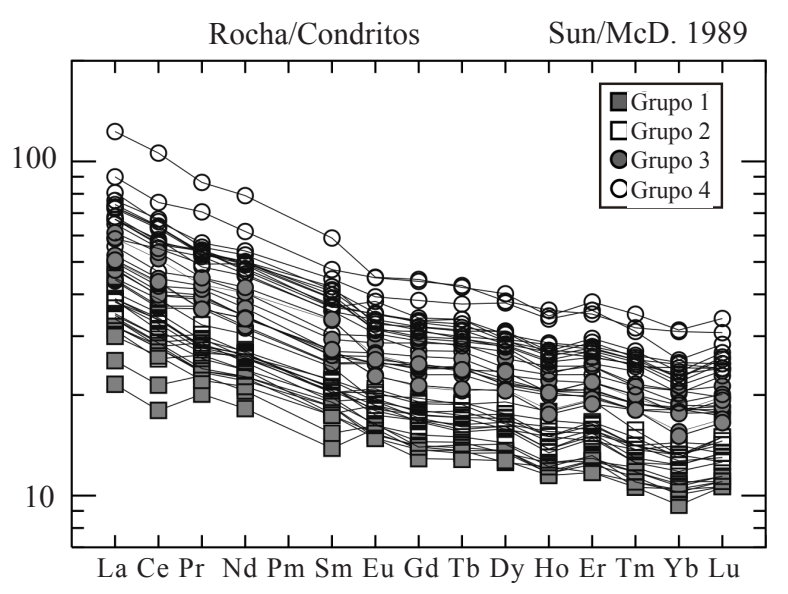

Figura 13 - Diagrama multielementar para Elementos Terras Raras normalizado pelos condritos de Sun \& McDonough (1989) para as rochas da soleira de Medicilândia. 
por fontes distintas, a segunda, mais provável, relaciona-se a diferentes taxas de fusão parcial de uma mesma fonte; nesse caso, a origem do grupo 4 estaria relacionada com uma taxa de fusão parcial menor do que para os grupos 1,2 e 3 . A terceira hipótese refere-se a diferentes taxas de cristalização fracionada, menor nas rochas dos grupos 1,2 e $3 \mathrm{em}$ relação às do grupo 4 .

Com o objetivo de verificar as três possíveis gêneses indicadas pela geoquímica de elementos traço e Terras Raras, foram elaborados os diagramas das Figuras 15 a 18 . No diagrama $\mathrm{La} \times \mathrm{Zr}(\mu \mathrm{g} / \mathrm{g})$ (Fig. 15), há correlação linear entre as rochas da soleira de Medicilândia, na qual o alinhamento dos pontos gera uma única reta que passa pela origem do diagrama. Essa reta indica a participação de fonte única na geração das rochas, excluindo a hipótese de fontes distintas, seguida por processo de cristalização fracionada.

De acordo com Allegre e Minster (1978), os elementos compatíveis variam "drasticamente", em concentração durante a cristalização fracionada, enquanto a concentração dos elementos incompatíveis varia significativamente em processos de fusão parcial. Desse modo, os diagramas das Figs. 16 e 17 indicam que as rochas dos grupos 1, 2, 3 e 4 da soleira de Medicilândia podem refletir diferenças no grau de fusão parcial da fonte. Assim, o grupo 1 teria sido originado por maior grau de fusão parcial que os demais grupos, pois apresenta, por exemplo, os menores teores de $\mathrm{Zr}$, que é um elemento incompatível. Observa-se variação nos teores em Co e Ni nos conjuntos de rochas dos grupos, indicando que houve processos de cristalização fracionada dentro de cada grupo, com fracionamento de piroxênio e magnetita.

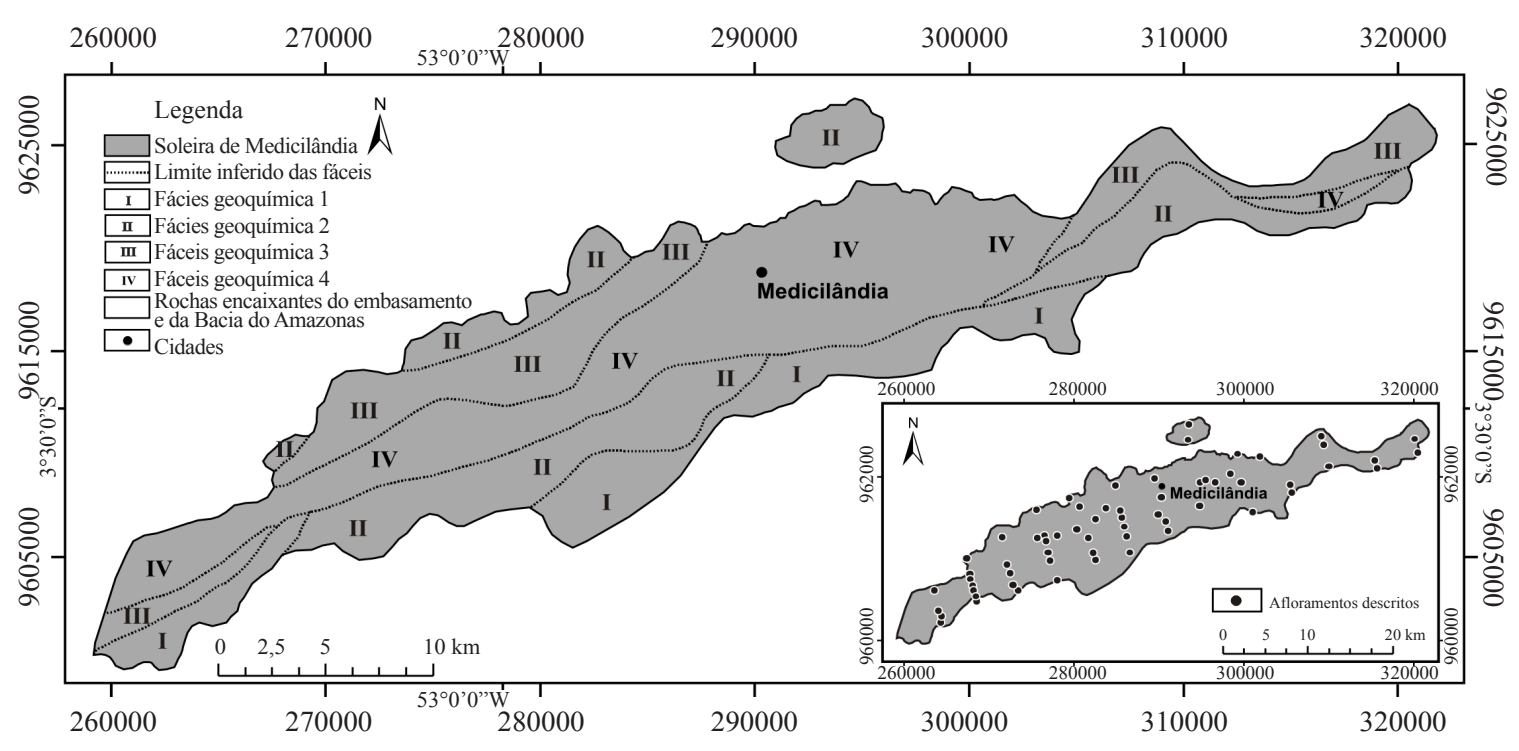

Figura 14 - Mapa de fácies geoquímicas da soleira de Medicilândia. No canto inferior direito, localização e distribuição dos afloramentos descritos.

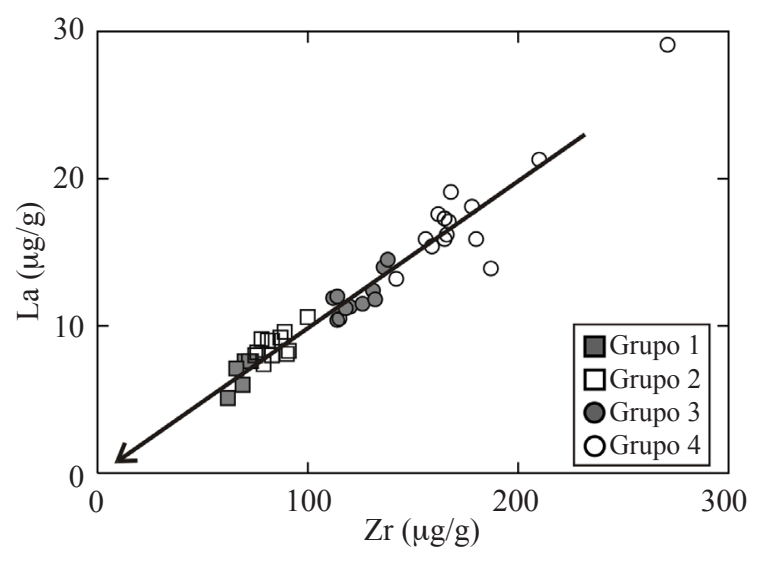

Figura 15 - Diagrama La $x$ Zr para as rochas da soleira de Medicilândia.

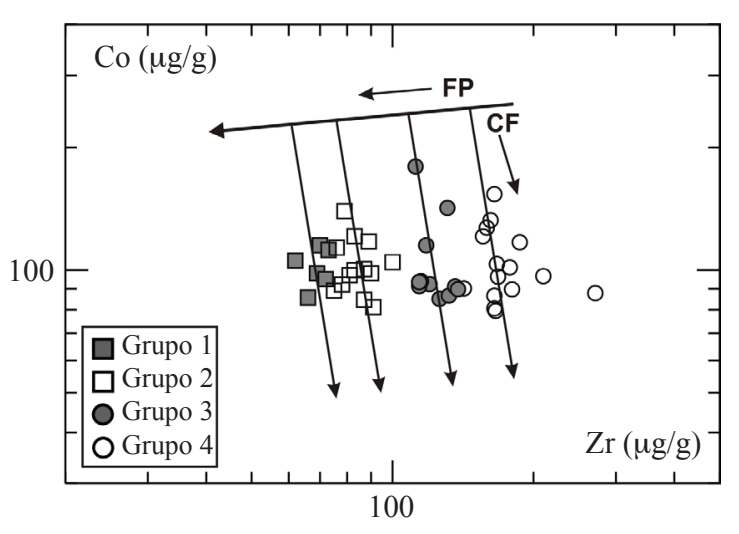

Figura 16 - Diagrama Co $x$ Zr para as rochas da soleira de Medicilândia. FP: fusão parcial, CF: cristalização fracionada. 
O diagrama de razão $\mathrm{Rb} / \mathrm{Sr} \times \mathrm{Rb}$ (Fig. 18) também permite distinguir os processos de fusão parcial entre os grupos de rocha e a cristalização fracionada ocorrida dentro de cada grupo.

CONSIDERAÇÕES FINAIS $\mathrm{Na}$ região de Medicilândia (PA), ocorre uma intrusão básica, denominada neste trabalho soleira de Medicilândia, cuja área aflorante abrange cerca de $300 \mathrm{~km}^{2}$ e que está encaixada em rochas sedimentares da Bacia do Amazonas. O litotipo predominante na soleira é o diabásio, ocorrendo gabro em porcentagem subordinada. A assembleia mineral primária de ambos os litotipos é composta por clinopiroxênio (augita), plagioclásio (andesina ou labradorita), minerais opacos, apatita e quartzo. Há paragênese de alteração hidrotermal marcante, representada por minerais opacos, sericita, clorita, uralita, hornblenda, biotita, quartzo e epidoto.

Os diabásios e gabros são rochas supersaturadas em $\mathrm{SiO}_{2}$ e são divididos em quatro grupos geoquímicos. A análise de mg* $(\mathrm{MgO} /(\mathrm{MgO}+\mathrm{FeO}))$ individualiza os grupos em: grupo geoquímico 1: mg* entre 0,5 e 0,6 e representa as rochas mais primitivas estudadas; grupos $2 \mathrm{e}$ 3 com valores de mg* intermediários, entre 0,4 e 0,5 e 0,3 e 0,4 respectivamente; e grupo 4: são as rochas mais evoluídas, com mg* entre 0,1 e 0,3 . Com exceção do grupo 4, no qual o teor de $\mathrm{TiO}_{2}$ está entre 2 e $3 \%$, todas as demais rochas possuem baixos teores de $\mathrm{TiO}_{2}(<2 \%)$.

Os diagramas de variação indicam que a evolução dos magmas se deu por processo de cristalização fracionada ou AFC, com possível mudança de assembleia fracionante evidenciada pela distribuição dos pontos em curvas polinomiais. $\mathrm{O}$ fracionamento de piroxênio é indicado nos diagramas que relacionam $\mathrm{MgO}$ com $\mathrm{CaO}$ e $\mathrm{Ni}$, e a ausência de anomalia negativa de Eu indica que o

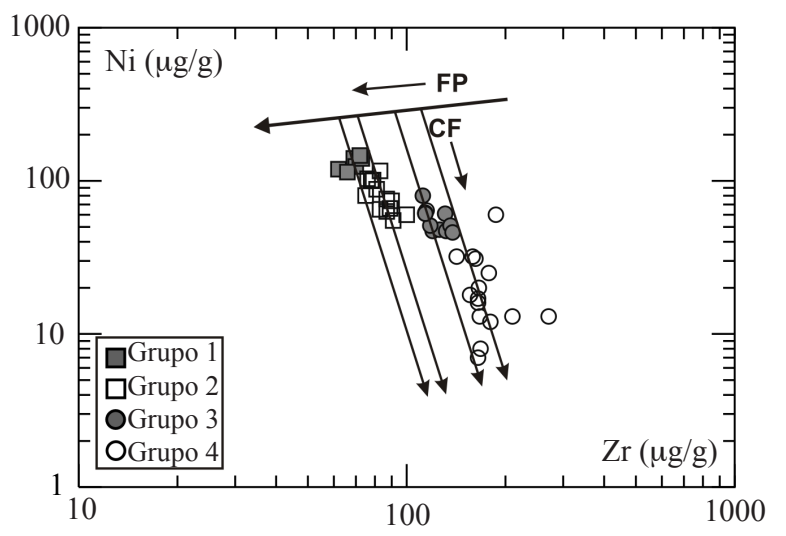

Figura 17 - Diagrama Ni $x \mathrm{Zr}$ para as rochas da soleira de Medicilândia. FP: fusão parcial, CF: cristalização fracionada. fracionamento de plagioclásio por cristalização fracionada não foi significativo.

Com base no diagrama R1R2, as rochas dos grupos 1 e 2 são classificadas como toleíto, do grupo 3 como andesi-basalto e do grupo 4 varia de basalto, andesi-basalto a lati-andesito. Nos diagramas AFM e de Jensen, os litotipos são classificadas como toleítos, com enriquecimento em $\mathrm{FeO}_{\mathrm{t}}$.

As assinaturas geoquímicas são semelhantes para todas as rochas, em diagramas multielementares para elementos traço e Terras Raras. O padrão geral da assinatura em diagrama multielementar para elementos traço é retilíneo, porém há anomalias positivas de Cs, $\mathrm{K}$ $\mathrm{e} \mathrm{Pb}$ e negativas de $\mathrm{Nb}$ e $\mathrm{P}$ para todas as rochas, e anomalia negativa de $\mathrm{Sr}$ para os grupos 3 e 4 . Em diagramas multielementares para elementos traço, observa-se fracionamento importante das rochas, em que as concentrações de Cs variam de 50 a 450 vezes o valor do manto primordial.

No diagrama de ETR, o fracionamento das rochas é evidenciado pela variação nas concentrações de La, que varia de 20 a 130 vezes maior que o teor do condrito. Os ETR leves são levemente mais enriquecidos do que os ETR pesados. Esse fato é um indício da ausência de granada na fonte, pois a presença de granada na fonte é geralmente indicada por uma depleção extrema de ETR pesados em relação aos leves.

Os diagramas de variação e de razão entre elementos traço indicam que a gênese da soleira de Medicilândia está relacionada a diferentes taxas de fusão parcial da mesma fonte, seguido por cristalização fracionada. Comparando-se os grupos geoquímicos, observa-se que a taxa de fusão parcial para a gênese do grupo 1 é a mais elevada. Essa taxa diminui para a geração das rochas dos grupos 2 e 3 e, no grupo 4, é a menos elevada. Em cada

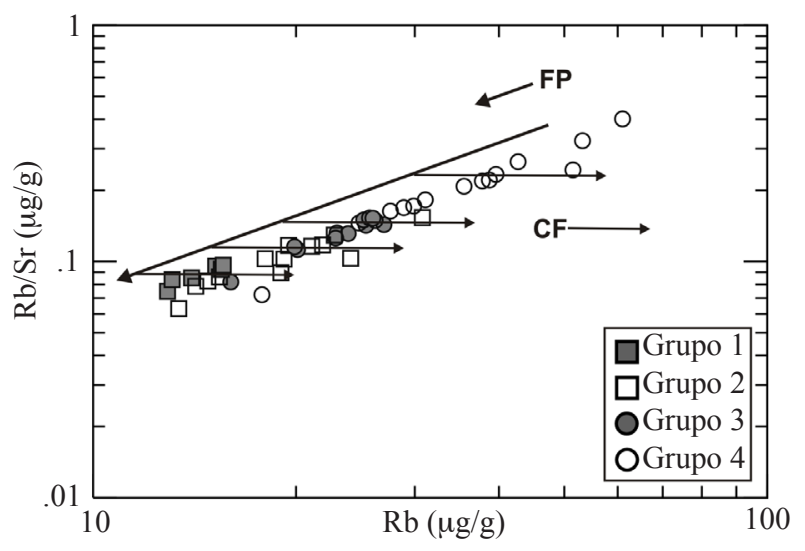

Figura 18 - Diagrama de razão $\mathrm{Rb} / \mathrm{Sr} \times \mathrm{Rb}$ para as rochas da soleira de Medicilândia. FP: fusão parcial, CF: cristalização fracionada. 
grupo, a evolução dos magmas ocorreu por processos de cristalização fracionada, conforme indicam os diagramas Co x Zr e Ni x Zr (Figs. 16 e 17).

O mapa faciológico indica a existência de um zoneamento geoquímico na soleira onde as fácies mais primitivas e formadas pelas maiores taxas de fusão parcial localizam-se nas bordas, enquanto as mais evoluídas geradas por menores taxas de fusão parcial concentram-se no centro da intrusão. Desse modo, a soleira de Medicilândia teve origem em um evento multi-intrusivo no qual os magmas dos primeiros pulsos (responsáveis pela geração das fácies 1, 2 e 3) são definidos como baixo $\mathrm{TiO}_{2}$, e o último pulso (fácies 4) é definido como magma de alto $\mathrm{TiO}_{2}$.

AGRADECIMENTOS Agradecimentos à CAPES, ao Programa de Pós-Graduação em Geologia da UFPR, ao LAMIR (Laboratório de Análise de Minerais e Rochas), ao LABAP (Laboratório de Análise de Bacias e Petrofísica) e à CPRM - Serviço Geológico do Brasil.

\section{Referências}

Alegre C.J. \& Minster J.F. 1978. Quantitave models of trace element behaviour in magnetic processes. Earth and Planetary Science Letters, 38:1-25.

Caputo M.V. 1984. Stratigraphy, tectonics, paleoclimatology and paleogeography of northern basins of Brazil. Tese de Doutorado, University of California, Santa Barbara, 586 p.

Coltice N., Bertrand H., Rey P., Jourdan F., Phillips B.R., Ricard Y. 2009. Global warming of the mantle beneath continents back to the Archean. Gondwana Research 15:254-266.

Coltice N., Phillips B.R., Bertrand H., Ricard Y., Rey P. 2007. Global warming of the mantle at the origin of flood basalts over supercontinents. Geology, 35:391-394.

De La Roche H., Leterrier J., Grandclaude P., Marchal M. 1980. A classification of volcanic and plutonic rocks using R1R2 - diagram and major element analyses - its relationships with current nomenclature. Chemical Geology, 29:183210.

Irvine T.N. \& Baragar W.R.A. 1971. A guide to the chemical classification of the common volcanic rocks. Canadian Journal of Earth Sciences, 8:523-548.

Issler R.S., Andrade A.R.F., Montalvão R.M.G., Silva G.G., Lima M.I.C. 1974. Geologia da folha S.A.22. Belém, Brasil. In: Departamento Nacional de Produção Mineral, Projeto RADAMBRASIL, Rio de Janeiro, DNPM, 5:1-60.

Jensen L.S. \& Pyke D.R. 1982. Komatiites in the Ontario portion of the Abitibi belt. In: Arndt N.T. \& Nisbet E.G. (eds.). Komatiites. London, George Allen and Unwin, p. 147-157.

Marzolli A., Renne P.A., Piccirillo E.M., Ernesto M., Bellieni G., De Min A. 1999. Extensive 200-million-year-old Continental Flood Basalts of the Central Atlantic Magmatic Province. Science. 284:616-618.

Middlemost E. A. K. 1989. Iron oxidation ratios, norms and the classification of volcanic rocks. Chemical Geology, 77:19-26.

Mizuzaki A.M.P \& Thomas Filho A. 2004. O magmatismo pós-paleozóico no Brasil. In: Mantesso-Neto V., Bartorelli A., Carneiro C.D.R., Brito Neves B.B. (eds.). Geologia do Continente Sul Americano: Evolução da obra de Fernando Flávio Marques de Ameida. São Paulo, Beca, p. 471-486.

Peate D.W., Hawkesworth C.J., Mantovani M.S.M. 1992.
Chemical startigraphy of the Paraná lavas (South America): classification of magma types and their spatial distribution. Bulletin of Vulcanology, 55:119-139.

Piccirillo E.M. \& Melfi A.J. 1988. The Mesozoic flood volcanism of the Paraná Basin: petrogenetic e geophysical aspects. Instituto Astronômico e Geofísico/ USP, São Paulo, 600p.

Santosh M., Maruyama S., Yamamoto S. 2009. The making and breaking of supercontinents: Some speculations based on superplumes, super downwelling and the role of tectosphere, Gondwana Research 15:324-341.

Sun S.S. \& McDonough W.F. 1989. Chemical and isotopic systematics of oceanic basalts: implications for mantle composition and processes. In: Sauders M.J. Magmatism in the ocean basins. Londres, Geological Society, Special Publication, 42:313-345.

Thomaz Filho A., Cordani U.G., Marino O. 1974. Idades $\mathrm{K}-\mathrm{Ar}$ de rochas basálticas da bacia Amazônica e sua significação tectônica regional. In: SBG, XXVIII Congresso Brasileiro de Geologia, Porto Alegre, 6:273-278.

Thomaz Filho A., Mizusaki A.M.P., Milani E.J., Cesero P. De. 2000. Rifting and magmatism associated with the South America and Africa breakup. Revista Brasileira de Geociências, 30:17-19.

Thomaz Filho A., Mizusaki A.M.P., Pimentel A.M., Antonioli L. 2008. Magmatism and the Petroleum Exploration in the Brazilian Paleozoic Basins. Marine and Petroleum Geology, 25:143-151.

Thorton C.P. \& Tuttle O.F. 1960. Chemistry of igneous rocks I. Differentiation index. American Journal Science, 258:664-684.

Wanderley Filho J.Q., Travassos W.A.S., Alves D.B. 2006. O diabásio nas bacias paleozóicas amazônicas - herói ou vilão? Boletim de Geociência da Petrobrás, Rio de Janeiro, 14:177-184. 